\title{
Total Synthesis of Iejimalide B. An Application of the Shiina Macrolactonization
}

Dirk Schweitzer, John J. Kane, Daniel Strand, Peter McHenry, ${ }^{*}$ Martin Tenniswood, ${ }^{*}$ and Paul Helquist ${ }^{*}$

Department of Chemistry and Biochemistry and Walther Cancer Research Center and Department of Biological Sciences ${ }^{\ddagger}$

University of Notre Dame, Notre Dame, Indiana 46556, U.S.A.

$$
\text { helquist.1@nd.edu }
$$

\section{Index}

General Methods

Synthesis and Analytical Data of C(1)-C(11) Sulfone 4

Synthesis and Analytical Data of C(12)-C(17) Aldehyde 7

Synthesis and Analytical Data of Racemic C(12)-C(19) Intermediate 8

Synthesis and Analytical Data of C(12)-C(19) Alkynyl Ketone 10

Synthesis and Analytical Data of C(12)-C(19) Intermediate (S)-8

Synthesis and Analytical Data of C(12)-C(19) Intermediate (S)-11

Synthesis and Analytical Data of the C(12)-C(19) Subunit (S)-12

Synthesis and Analytical Data of the Completed C(1)-C(19) Subunit S-8

Synthesis and Analytical Data of the O-TBS-protected Iejimalide Side Chain $\quad$ S-9

Synthesis and Analytical Data of Iejimalide Side Chain Aldehyde $18 \quad$ S-10

Synthesis and Analytical Data of C(20)-C(34) Alkyne $20 \quad$ S-10

Synthesis and Analytical Data of (C20)-C(34) Vinyl Stannane $21 \quad$ S-11

Synthesis and Analytical Data of O-TBS-protected Iejimalide B (22) S-12

Synthesis and Analytical Data of Iejimalide B (1) S-14

$\begin{array}{ll}\text { Crystal Violet Cell Number Assay } & \text { S-15 }\end{array}$

$\begin{array}{ll}\text { References } & \text { S-15 }\end{array}$ 
${ }^{1} \mathrm{H}$ NMR and ${ }^{13} \mathrm{C}$ NMR Spectra of Compound $4 \quad$ S-16

${ }^{1} \mathrm{H}$ NMR and ${ }^{13} \mathrm{C}$ NMR Spectra of Compound $7 \quad$ S-18

${ }^{1}$ H NMR and ${ }^{13}$ C NMR Spectra of Compound (S)-8 $\quad$ S-20

${ }^{1} \mathrm{H}$ NMR and ${ }^{13} \mathrm{C}$ NMR Spectra of Compound $10 \quad$ S-22

${ }^{1} \mathrm{H}$ NMR and ${ }^{13} \mathrm{C}$ NMR Spectra of Compound $11 \quad$ S-24

${ }^{1} \mathrm{H}$ NMR and ${ }^{13} \mathrm{C}$ NMR Spectra of Compound $12 \quad$ S-26

${ }^{1}$ H NMR and ${ }^{13}$ C NMR Spectra of Compound $13 \quad$ S-28

${ }^{1} \mathrm{H}$ NMR and ${ }^{13} \mathrm{C}$ NMR Spectra of Compound $\mathbf{1 7} \quad$ S-30

${ }^{1} \mathrm{H}$ NMR and ${ }^{13} \mathrm{C}$ NMR Spectra of Compound $18 \quad$ S-32

${ }^{1} \mathrm{H}$ NMR and ${ }^{13} \mathrm{C}$ NMR Spectra of Compound $20 \quad$ S-34

${ }^{1} \mathrm{H}$ NMR and ${ }^{13} \mathrm{C}$ NMR Spectra of Compound $21 \quad$ S-36

${ }^{1}$ H NMR Spectra of $O$-TBS-Iejimalide B (22) S-38

Comparison of the ${ }^{1}$ H NMR Spectra of Natural and Synthetic Iejimalide B $\quad$ S-39

\section{General Methods.}

Unless stated otherwise, all reagents and solvents were used as received from commercial suppliers. Unless stated otherwise, all reactions were conducted in dried, anhydrous solvents. Triethylamine $\left(\mathrm{Et}_{3} \mathrm{~N}\right)$ was distilled from $\mathrm{CaH}_{2}$ under an $\mathrm{Ar}$ atmosphere and stored over $\mathrm{CaH}_{2}$. All moisture sensitive reactions were performed using dried solvent in flame-dried glassware under an atmosphere of Ar. All low temperature reactions were performed under an atmosphere of Ar. All reactions were stirred. Schwartz' reagent $\left(\mathrm{Cp}_{2} \mathrm{ZrHCl}\right)$ and $\mathrm{Zn}(\mathrm{OTf})_{2}$ were stored in a glove box. Whenever the contents of a flask were dried on a high vacuum line prior to conducting the reaction, also the magnetic stirring bar was present. Filtration was generally performed through a pad of Celite. TLC analyses were performed on Merck aluminum-backed F254 silica gel plates. Flash chromatography was performed using silica gel (ICN $60 \AA$ silica gel, 32-63 $\mu$ ) and samples were applied using PhMe containing, if necessary, some $\mathrm{CH}_{2} \mathrm{Cl}_{2}$. NMR spectra were measured at the frequencies indicated on a $300 \mathrm{MHz}$ Varian, $400 \mathrm{MHz}$ Bruker, or $500 \mathrm{MHz}$ Varian instrument. All ${ }^{1} \mathrm{H}$ chemical shifts $(\delta)$ are relative to residual protic solvent $\left(\mathrm{CHCl}_{3}: \delta 7.26 \mathrm{ppm}\right)$, and all ${ }^{13} \mathrm{C}$ chemical shifts $(\delta)$ are relative to the solvent $\left(\mathrm{CDCl}_{3}: \delta 77.23 \mathrm{ppm}\right)$. Mass spectral data were measured on a JEOL JMS-AX505 HA spectrometer. Infrared spectra were recorded on a Perkin-Elmer Paragon 1000 FT-IR spectrophotometer as neat thin films between $\mathrm{NaCl}$ plates in the case of liquid substances 
or as $\mathrm{KBr}$ pellets in the case of solids. Optical rotations were determined using the sodium D line $(589 \mathrm{~nm})$. All HPLC separations were performed using a C18 reverse phase column (RCM $8 \times 10$, Radial-Pak Cartridge, Type: 8 NV C18 $4 \mu$ ) on a Waters ${ }^{\circledR}$ HPLC system.

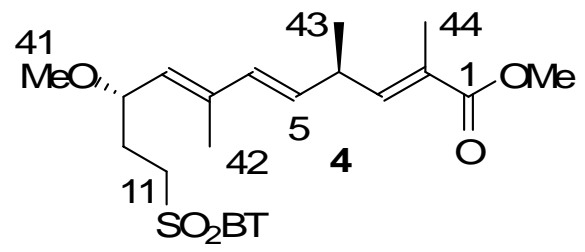

\section{C(1)-C(11) Sulfone 4.}

Following the procedure of LaFontaine, ${ }^{1} \mathrm{C}(6)-\mathrm{C}(11)$ aldehyde 3 (292 mg, 0.767 $\mathrm{mmol})^{2}$ and $\mathrm{C}(1)-\mathrm{C}(5)$ sulfone $2(260 \mathrm{mg}, 0.767 \mathrm{mmol})^{2}$ were placed in the same flask and dissolved in Acros dry THF $(29 \mathrm{~mL})$. The solution was cooled to $-78{ }^{\circ} \mathrm{C}$, LiHMDS ( $2.30 \mathrm{~mL}$ of an $1.0 \mathrm{M}$ solution in THF, $2.30 \mathrm{mmol}, 3$ equiv) was added dropwise, and the solution was stirred at $-78{ }^{\circ} \mathrm{C}$ for $2 \mathrm{~h}$. The Dewar flask was removed, allowing the solution to warm to $23{ }^{\circ} \mathrm{C}$ over the course of $30 \mathrm{~min}$. Then the reaction was quenched with sat. aq. $\mathrm{NH}_{4} \mathrm{Cl}$ and extracted $3 \times$ with $\mathrm{CH}_{2} \mathrm{Cl}_{2}$. The combined organic phase was evaporated to dryness, and the residue was dissolved in $\mathrm{MeOH}(\mathrm{c}=0.1 \mathrm{M}) . \mathrm{NH}_{4} \mathrm{~F}(20$ equiv) was added, and the reaction was stirred for $24 \mathrm{~h}$ at $23{ }^{\circ} \mathrm{C}$. The reaction was quenched with sat. aq. $\mathrm{NaHCO}_{3}$ and extracted $3 \times$ with $\mathrm{CH}_{2} \mathrm{Cl}_{2}$. The combined organic phase was evaporated to dryness, and the crude product was purified by silica gel chromatography $(2.8$ x $23.5 \mathrm{~cm}$, gradient: $200 / 10$ hexanes/EtOAc $\rightarrow 56 \%$ EtOAc/hexanes) (105 mg, $0.37 \mathrm{mmol}, 73 \%$ yield over 2 steps, $E / Z=12 / 1$ based on $E\left(\mathrm{H}_{6}\right)[\mathrm{d}, 6.06 \mathrm{ppm}]$ to $\left.\mathrm{Z}\left(\mathrm{H}_{6}\right)[\mathrm{d}, 5.80 \mathrm{ppm}]\right)\left(\mathrm{R}_{\mathrm{f}}=0.15 \mathrm{using} 40 \%\right.$ EtOAc/hexanes $)$.

The intermediate alcohol (105 mg, $0.37 \mathrm{mmol}), \mathrm{PPh}_{3}(107 \mathrm{mg}, 0.41 \mathrm{mmol})$, and 2-mercaptobenzothiazole $(68 \mathrm{mg}, 0.41 \mathrm{mmol})$ were dissolved in anhydrous benzene ( 8 $\mathrm{mL}$, Aldrich), and a solution of dimethylazodicarboxylate in toluene $(151 \mu \mathrm{L}, 2.71$ $\mathrm{mmol} / \mathrm{mL}, 0.41 \mathrm{mmol}$ ) was slowly added dropwise to the rapidly stirring solution. After stirring overnight at $23{ }^{\circ} \mathrm{C}$, all solvent was removed on a rotary evaporator. The intermediate benzothiazole-sulfide was used immediately for the oxidation to the sulfone.

The contents of the flask were dissolved in $\mathrm{MeOH}(6 \mathrm{~mL})$ and cooled to $0{ }^{\circ} \mathrm{C}$. In a separate flask, $\left(\mathrm{NH}_{4}\right)_{6} \mathrm{Mo}_{7} \mathrm{O}_{24} \times 4 \mathrm{H}_{2} \mathrm{O}(457 \mathrm{mg}, 0.37 \mathrm{mmol})$ and $30 \%$ aq. $\mathrm{H}_{2} \mathrm{O}_{2}(0.75$ $\mathrm{mL}, 7.4 \mathrm{mmol}, \mathrm{c}=9.8093 \mathrm{~mol} / \mathrm{L}$ ) were combined and likewise cooled to $0{ }^{\circ} \mathrm{C}$. The $\mathrm{H}_{2} \mathrm{O}_{2}-$ containing solution was added dropwise to the $\mathrm{MeOH}$ solution. The combined solution was stirred for $11 \mathrm{~h}$ at $0{ }^{\circ} \mathrm{C}$, and then diluted with $\mathrm{H}_{2} \mathrm{O}$ and $3 \times$ extracted with $\mathrm{CH}_{2} \mathrm{Cl}_{2}$. The combined organic phase was dried over $\mathrm{MgSO}_{4}$, and filtered, and all volatiles were evaporated. The remaining residue was purified by silica gel chromatography $(2.8 \times 21$ $\mathrm{cm}$, gradient: $200 / 10$ hexanes/EtOAc $\rightarrow 38 \%$ EtOAc/hexanes) to yield the product as a colorless oil (110 mg, $0.24 \mathrm{mmol}, 64 \%$ yield over 2 steps $)\left(\mathrm{R}_{\mathrm{f}}=0.44\right.$ using $40 \%$ EtOAc/hexanes). ${ }^{1} \mathrm{H}$ NMR $\left(500 \mathrm{MHz}, \mathrm{CDCl}_{3}, 23{ }^{\circ} \mathrm{C}\right): \delta=8.20$ (ddd, $J=8.2,1.3,0.7 \mathrm{~Hz}$, $1 \mathrm{H}$, aromatic), 8.00 (ddd, $J=7.9,1.4,0.7 \mathrm{~Hz}, 1 \mathrm{H}$, aromatic), 7.60 (m, $2 \mathrm{H}$, aromatic), $6.58\left(\mathrm{dq}, J=9.8,1.4 \mathrm{~Hz}, 1 \mathrm{H}, \mathrm{H}_{3}\right), 6.01\left(\mathrm{~d}, J=15.8 \mathrm{~Hz}, 1 \mathrm{H}, \mathrm{H}_{6}\right), 5.58$ (dd, $J=15.6,6.7$ $\left.\mathrm{Hz}, 1 \mathrm{H}, \mathrm{H}_{5}\right), 5.18\left(\mathrm{~d}, J=8.9 \mathrm{~Hz}, 1 \mathrm{H}, \mathrm{H}_{8}\right), 4.14\left(\mathrm{~m}, 1 \mathrm{H}, \mathrm{H}_{9}\right), 3.72\left(\mathrm{~s}, 3 \mathrm{H}, \mathrm{CO}_{2} \mathrm{CH}_{3}\right)$, $3.60\left(\mathrm{~m}, 2 \mathrm{H}, \mathrm{H}_{11}\right), 3.25\left(\mathrm{~m}, 1 \mathrm{H}, \mathrm{H}_{4}\right), 3.18\left(\mathrm{~s}, 3 \mathrm{H}, \mathrm{H}_{41}\right), 2.04\left(\mathrm{~m}, 2 \mathrm{H}, \mathrm{H}_{10}\right), 1.85(\mathrm{~d}, J=$ $\left.1.5 \mathrm{~Hz}, 3 \mathrm{H}, \mathrm{H}_{44}\right), 1.75\left(\mathrm{~d}, J=1.2 \mathrm{~Hz}, 3 \mathrm{H}, \mathrm{H}_{42}\right), 1.13 \mathrm{ppm}\left(\mathrm{d}, J=6.8 \mathrm{~Hz}, 3 \mathrm{H}, \mathrm{H}_{43}\right) .{ }^{13} \mathrm{C}$ 
NMR $\left(125 \mathrm{MHz}, \mathrm{CDCl}_{3}, 23{ }^{\circ} \mathrm{C}\right): \delta=168.9,165.8,152.9,145.0,137.9,136.9,133.1$, $132.4,129.9,128.2,127.8,126.7,125.6,122.5,75.0,56.2,52.0,51.4,36.4,28.5,20.4$, 13.2, 12.7 ppm. IR: $2928,1712,1473,1330,1151,1093,763 \mathrm{~cm}^{-1} .[\alpha]^{23}{ }_{\mathrm{D}}-30.3(\mathrm{c}=$ 0.00554, $\left.\mathrm{CHCl}_{3}\right)$. HRMS (FAB+) $\mathrm{m} / \mathrm{z}\left(\left[\mathrm{M}-\mathrm{CH}_{3} \mathrm{O}\right]^{+}\right)$: Calcd for $\mathrm{C}_{22} \mathrm{H}_{26} \mathrm{~N}_{1} \mathrm{O}_{4} \mathrm{~S}_{2}: 432.1303$, Found: 432.1307.

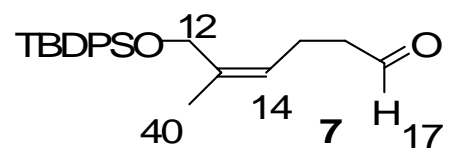

C(12)-C(17) Aldehyde 7.

In a flame-dried 250 -mL flask, 4-O-TBS-butyltriphenylphosphonium iodide (5) ${ }^{3}$ $(6.34 \mathrm{~g}, 11.1 \mathrm{mmol})$ was dried under high vacuum for $1 \mathrm{~h}$. Under Ar, it was dissolved in fresh, dry THF $(45 \mathrm{~mL})$, and $n$-BuLi $(4.4 \mathrm{~mL}$ of a $2.4 \mathrm{M}$ solution in THF, $10.5 \mathrm{mmol})$ was added dropwise. After stirring for $1 \mathrm{~h}$ at $23{ }^{\circ} \mathrm{C}$, the flask containing the deep-red suspension was cooled to $-78^{\circ} \mathrm{C}$, and a precooled $\left(-78^{\circ} \mathrm{C}\right)$ solution of 1-O-TBS-propan2-one $(6)^{4}(3.45 \mathrm{~g}, 11.1 \mathrm{mmol})$ in THF $(75 \mathrm{~mL})$ was added through a cannula. After stirring for an additional $8 \mathrm{~h}$, the reaction was allowed to slowly warm to $23{ }^{\circ} \mathrm{C}$ overnight. The reaction was quenched with sat. aq. $\mathrm{NH}_{4} \mathrm{Cl}$ and some $\mathrm{H}_{2} \mathrm{O}$ and extracted $\left(1 \times \mathrm{Et}_{2} \mathrm{O}, 2 \times \mathrm{CH}_{2} \mathrm{Cl}_{2}\right)$. The combined organic phase was dried $\left(\mathrm{MgSO}_{4}\right)$, filtered, and concentrated. The residue was purified by chromatography $\left(\mathrm{SiO}_{2}, 2.8 \times 20 \mathrm{~cm}\right.$, gradient: $100 \% \mathrm{CH}_{2} \mathrm{Cl}_{2} \rightarrow 3.8 \% \mathrm{EtOAc} / \mathrm{CH}_{2} \mathrm{Cl}_{2}$ ) to provide the desired olefinic product as a nearly colorless oil $(4.04 \mathrm{~g}, 8.36 \mathrm{mmol}, 14 \mathrm{E} / \mathrm{Z}=1 / 10,80 \%$ yield $)\left(\mathrm{R}_{\mathrm{f}}=0.80\right.$ using $40 \%$ EtOAc/hexanes).

The olefinic product of the last reaction $(750 \mathrm{mg}, 1.55 \mathrm{mmol})$ was dissolved in EtOH $(24 \mathrm{~mL}$, absolute, 200 proof) and pyridinium $p$-toluenesulfonate (Py-p-TSA, PPTS) $\left(91 \mathrm{mg}, 0.36 \mathrm{mmol}\right.$ ) was added. After stirring for $24 \mathrm{~h}$ at $23{ }^{\circ} \mathrm{C}$, the solution was concentrated by rotary evaporation followed by high vacuum, and the remaining residue was purified by a flash chromatography column $\left(\mathrm{SiO}_{2}, 2.8 \times 19 \mathrm{~cm}\right.$, gradient: $100 \%$ hexanes $\rightarrow 33 \%$ EtOAc/hexanes) to provide the O-TBS-deprotected alcohol as a colorless oil (542 mg, $1.47 \mathrm{mmol}, 95 \%$ yield) $\left(\mathrm{R}_{\mathrm{f}}=0.40\right.$ using $40 \%$ EtOAc/hexanes).

The alcohol product of the previous reaction $(502 \mathrm{mg}, 1.36 \mathrm{mmol})$ was dissolved in DMSO $(4 \mathrm{~mL})$ and $\mathrm{NEt}_{3}(1.2 \mathrm{~mL})$. A solution of $\mathrm{SO}_{3} \bullet \mathrm{Py}(649 \mathrm{mg}, 4.08 \mathrm{mmol})$ in DMSO $(4 \mathrm{~mL})$ was added at $23{ }^{\circ} \mathrm{C} .{ }^{5}$ After stirring for $20 \mathrm{~min}$, the reaction was quenched with ice-water, and extracted with $\mathrm{Et}_{2} \mathrm{O}$. The organic phase was washed with water and brine, dried $\left(\mathrm{MgSO}_{4}\right)$, filtered, and concentrated to dryness. The remaining residue was purified by a flash chromatography column $\left(\mathrm{SiO}_{2}, 2.8 \times 19 \mathrm{~cm}\right.$, gradient: $100 \%$ hexanes $\rightarrow 29 \%$ EtOAc/hexanes) to provide the desired aldehyde (7) as a colorless oil $(477 \mathrm{mg}$, $1.30 \mathrm{mmol}, 95 \%$ yield) $\left(\mathrm{R}_{\mathrm{f}}=0.60\right.$ using $40 \%$ EtOAc/hexanes). ${ }^{1} \mathrm{H}$ NMR $(400 \mathrm{MHz}$, $\left.\mathrm{CDCl}_{3}, 23{ }^{\circ} \mathrm{C}\right): \delta=9.64\left(\mathrm{t}, J=1.4 \mathrm{~Hz}, 1 \mathrm{H}, \mathrm{H}_{17}\right), 7.73-7.63(\mathrm{~m}, 4 \mathrm{H}, \mathrm{Ph}), 7.46-7.34(\mathrm{~m}, 6$ $\mathrm{H}, \mathrm{Ph}), 5.42\left(\mathrm{t}, J=7.0 \mathrm{~Hz}, 1 \mathrm{H}, \mathrm{H}_{14}, E=\right.$ minor), $5.13\left(\mathrm{t}, J=6.9 \mathrm{~Hz}, 1 \mathrm{H}, \mathrm{H}_{14}, Z=\right.$ major), 4.19 (s, $2 \mathrm{H}, \mathrm{H}_{12}, Z$ = major), 4.06 (s, $2 \mathrm{H}, \mathrm{H}_{12}, E=$ minor), 2.32 (dt, $J=7.3,1.0 \mathrm{~Hz}, 2 \mathrm{H}$, $\mathrm{H}_{16}$ ), 2.12 (ap. q, $2 \mathrm{H}, \mathrm{H}_{15}$ ), 1.82 (d, $J=0.6 \mathrm{~Hz}, 3 \mathrm{H}, \mathrm{H}_{40}$ ), 1.05 ppm (s, $9 \mathrm{H}$, tert-Butyl). ${ }^{13} \mathrm{C}$ NMR $\left(100 \mathrm{MHz}, \mathrm{CDCl}_{3}, 23{ }^{\circ} \mathrm{C}\right): \delta=202.1,136.2,135.6,135.5,133.7,129.6,129.5$, 127.7, 127.6, 127.5, 124.0, 62.4, 43.9, 26.8, 21.2, 20.2, 19.3 ppm. IR: 2931, 2857, 1722, 1471, 1112, 832, $701 \mathrm{~cm}^{-1}$. HRMS $(\mathrm{FAB}+) \mathrm{m} / \mathrm{z}\left([\mathrm{M}-\mathrm{H}]^{+}\right)$: Calcd for $\mathrm{C}_{23} \mathrm{H}_{29} \mathrm{O}_{2} \mathrm{Si}_{1}$ : 365.1937, Found: 365.1934 . 


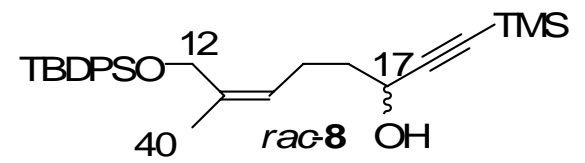

\section{Racemic C(12)-O-TBDPS-C(17)-OH-C(19)-TMS-C(12)-C(19) Subunit Intermediate rac-8.}

A solution of trimethylsilylacetylene $(405 \mu \mathrm{L}, 2.86 \mathrm{mmol})$ in THF $(6 \mathrm{~mL})$ was cooled to $0{ }^{\circ} \mathrm{C}$ under $\mathrm{Ar}, n$-BuLi $(0.80 \mathrm{~mL}$ of a $2.4 \mathrm{M}$ solution in THF, $1.90 \mathrm{mmol})$ was added dropwise. After stirring for $30 \mathrm{~min}$ at $0{ }^{\circ} \mathrm{C}$, a solution of aldehyde 7 (233 $\mathrm{mg}, 0.64$ $\mathrm{mmol})$ in THF $(3.0 \mathrm{~mL})$ was added dropwise, followed by washing with additional THF $(3 \times 1.5 \mathrm{~mL})$. While still at $0{ }^{\circ} \mathrm{C}$, the reaction was quenched with sat. aq. $\mathrm{NH}_{4} \mathrm{Cl} 4.5 \mathrm{~h}$ later and extracted with $\mathrm{CH}_{2} \mathrm{Cl}_{2}(3 \times)$. The combined organic extracts were dried (MgSO4), filtered, and concentrated. The remaining residue was purified by chromatography $\left(\mathrm{SiO}_{2}, 2.8\right.$ x $22 \mathrm{~cm}$, gradient: 4.7\% EtOAc/hexanes $\rightarrow$ 17\% EtOAc/hexanes) to provide the desired product (rac-8) as a colorless oil (285 mg, 0.61 mmol, 96\% yield) ( $\mathrm{R}_{\mathrm{f}}=0.60$ using $40 \%$ EtOAc/hexanes). The ${ }^{1} \mathrm{H}$ NMR spectrum was identical to the spectrum obtained for the enantiomerically enriched material below.

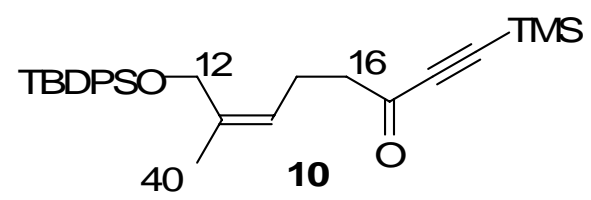

\section{C(12)-C(19) Alkynyl Ketone 10.}

Racemic C(12)-C(19) propargylic alcohol 8 (256 $\mathrm{mg}, 0.55 \mathrm{mmol})$ was dissolved in dry $\mathrm{CH}_{2} \mathrm{Cl}_{2}(27 \mathrm{~mL})$ and freshly dried molecular sieves (4 $\left.\AA, 298 \mathrm{mg}\right)$ were added. After stirring for $15 \mathrm{~min}$ at $23{ }^{\circ} \mathrm{C}$ under Ar, pyridinium dichromate (PDC, $437 \mathrm{mg}, 1.16$ mmol) was added, and the reaction was stirred overnight. The reaction was filtered through Celite and neutral aluminum oxide (Brockmann I, Aldrich 199974), washed with $\mathrm{CH}_{2} \mathrm{Cl}_{2}$, and concentrated. Chromatography $\left(\mathrm{SiO}_{2}, 2.8 \times 22 \mathrm{~cm}\right.$, gradient: $4.7 \%$ EtOAc/hexanes $\rightarrow 13 \%$ EtOAc/hexanes) provided the desired alkynyl ketone 10 as a colorless oil (208 mg, $0.45 \mathrm{mmol}, 85 \%$ yield) $\left(\mathrm{R}_{\mathrm{f}}=0.66 \mathrm{using} 40 \%\right.$ EtOAc/hexanes $) .{ }^{1} \mathrm{H}$ NMR (300 MHz, $\left.\mathrm{CDCl}_{3}, 23{ }^{\circ} \mathrm{C}\right): \delta=7.73-7.63(\mathrm{~m}, 4 \mathrm{H}, \mathrm{Ph}), 7.46-7.34(\mathrm{~m}, 6 \mathrm{H}, \mathrm{Ph}), 5.42$ (t, $J=7.0 \mathrm{~Hz}, 1 \mathrm{H}, \mathrm{H}_{14}, E=$ minor), 5.17 (t, $J=7.3 \mathrm{~Hz}, 1 \mathrm{H}, \mathrm{H}_{14}, Z=$ major), 4.22 (s, $2 \mathrm{H}$, $\mathrm{H}_{12}, \mathrm{Z}=$ major), 4.06 (s, $2 \mathrm{H}, \mathrm{H}_{12}, E=$ minor), 2.62 (t, $2 \mathrm{H}, J=7.8 \mathrm{~Hz}, \mathrm{H}_{16}, E=$ minor), 2.50 (t, $2 \mathrm{H}, J=7.4 \mathrm{~Hz}, \mathrm{H}_{16}, Z=$ major), 2.18 (ap. q, $2 \mathrm{H}, J=7.4 \mathrm{~Hz}, \mathrm{H}_{15}$ ), 1.84 (s, $3 \mathrm{H}$, $\left.\mathrm{H}_{40}\right), 1.08$ (s, $9 \mathrm{H}$, tert-Butyl), $0.24 \mathrm{ppm}\left(\mathrm{s}, 9 \mathrm{H}, \mathrm{SiMe}_{3}\right) .{ }^{13} \mathrm{C} \mathrm{NMR}\left(75 \mathrm{MHz}, \mathrm{CDCl}_{3}, 23\right.$ $\left.{ }^{\circ} \mathrm{C}\right): \delta=187.2$, 136.3, 135.8, 133.9, 129.8, 127.9, 124.1, 102.1, 97.9, 62.6, 45.6, 27.0, 22.1, 21.4, 19.5, - 0.6 ppm. IR: 2969, 2151, 1683, 1428, 1253, 1112, 847, $702 \mathrm{~cm}^{-1}$. HRMS (FAB+) $m / z\left([M-H]^{+}\right)$: Calcd for $\mathrm{C}_{28} \mathrm{H}_{38} \mathrm{O}_{2} \mathrm{Si}_{2}$ : 461.2332, Found: 461.2361. 


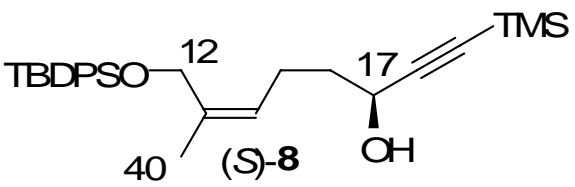

$\mathrm{C}(12)-O-T B D P S-\mathrm{C}(17)-\mathrm{OH}-\mathrm{C}(17)-(S)-\mathrm{C}(19)-\mathrm{TMS}$ Intermediate of the $\mathrm{C}(12)-\mathrm{C}(19)$ Subunit: (S)-8.

(A) Via enantioselective reduction. ${ }^{6}$ To a dry $15-\mathrm{mL}$ flask were added under $\mathrm{Ar}(S)$ Alpine borane $(2.0 \mathrm{~mL}$ of $0.5 \mathrm{M}$ solution in THF, $1 \mathrm{mmol})$. After cooling to $0{ }^{\circ} \mathrm{C}$, propargylic ketone $10(229 \mathrm{mg}, 0.49 \mathrm{mmol})$ in $\mathrm{CH}_{2} \mathrm{Cl}_{2}(1.5 \mathrm{~mL})$ was added, and the mixture was concentrated immediately on a rotary evaporator to an oil to permit the reaction to occur at high concentration. The oil was stirred at $23{ }^{\circ} \mathrm{C}$ overnight, diluted with $\mathrm{Et}_{2} \mathrm{O}$, cooled to $0{ }^{\circ} \mathrm{C}$, and acetaldehyde $(1 \mathrm{~mL})$ and ethanolamine $(1 \mathrm{~mL})$ were added. After filtration and concentration, the residue was purified twice by flash chromatography $\left(\mathrm{SiO}_{2}, \quad 2.8 \times 22 \mathrm{~cm}\right.$, gradient: $4.7 \%$ EtOAc/hexanes $\rightarrow \quad 17 \%$ EtOAc/hexanes) to provide the desired product $((S)-8)$ as a colorless oil $(195 \mathrm{mg}, 0.42$ mmol, $86 \%$ yield) ( $\mathrm{R}_{\mathrm{f}}=0.60$ using $40 \%$ EtOAc/hexanes). The material was shown to have an ee of $91 \%(95.5 \% S \& 4.5 \% R)$ by the formation of Mosher esters.

(B) Via Carreira chemistry. To a solution of $\mathrm{Zn}(\mathrm{OTf})_{2}(343 \mathrm{mg}, 0.946 \mathrm{mmol})$ and $(1 S, 2 R)-N-(-)$-methylephedrine (184 mg, $1.03 \mathrm{mmol})$ in PhMe $(1.5 \mathrm{~mL})$ was added $\mathrm{Et}_{3} \mathrm{~N}$ $(122 \mu \mathrm{L}, 1.20 \mathrm{mmol})$ through a septum. The resulting slurry was stirred for $2 \mathrm{~h}$, and then trimethylsilylacetylene $(606 \mu \mathrm{L}, 4.3 \mathrm{mmol})$ was added. After $15 \mathrm{~min}$, a solution of aldehyde 7 (315 mg, $0.86 \mathrm{mmol})$ in PhMe $(1 \mathrm{~mL})$ was added via a syringe (rinsed with $0.5 \mathrm{~mL} \mathrm{PhMe}$ ). The reaction vessel was then sealed with a screw cap and placed into a 55 ${ }^{\circ} \mathrm{C}$ oilbath. After $21 \mathrm{~h}$, the reaction mixture was poured into sat. aq. $\mathrm{NH}_{4} \mathrm{Cl}$ and partitioned between $\mathrm{Et}_{2} \mathrm{O}$ and the aqueous phase. The combined organic phases were dried $\left(\mathrm{MgSO}_{4}\right)$, filtered, and concentrated. Purification by flash chromatography $\left(\mathrm{SiO}_{2}\right.$, 3.13-6.25\% EtOAc/hexanes) afforded propargylic alcohol (S)-8 as a clear oil (169 mg, $54 \%)$. The material was shown to have an ee of $94 \%(97 \% S \& 3 \% R)$ by the formation of Mosher esters. ${ }^{1} \mathrm{H}$ NMR $\left(400 \mathrm{MHz}, \mathrm{CDCl}_{3}, 23{ }^{\circ} \mathrm{C}\right): \delta=7.74-7.66$ (m, $\left.4 \mathrm{H}, \mathrm{Ph}\right), 7.47-$ $7.35(\mathrm{~m}, 6 \mathrm{H}, \mathrm{Ph}), 5.46\left(\mathrm{dt}, J=7.4,1.3 \mathrm{~Hz}, 1 \mathrm{H}, \mathrm{H}_{14}, E=\right.$ minor), 5.21 (dt, $J=7.4,1.0$ $\mathrm{Hz}, 1 \mathrm{H}, \mathrm{H}_{14}, \mathrm{Z}$ = major), 4.27-4.17 (m, $\left.3 \mathrm{H}, \mathrm{H}_{12}, \mathrm{H}_{17}\right), 2.00\left(\mathrm{~m}, 2 \mathrm{H}, \mathrm{H}_{15}\right), 1.83$ (d, $J=1.0$ $\left.\mathrm{Hz}, 3 \mathrm{H}, \mathrm{H}_{40}\right), 1.69-1.58\left(\mathrm{~m}, 2 \mathrm{H}, \mathrm{H}_{16}\right), 1.07$ (s, $9 \mathrm{H}$, tert-Butyl), $0.14 \mathrm{ppm}(\mathrm{s}, 9 \mathrm{H}$, $\left.\mathrm{Si}(\mathrm{Me})_{3}\right) \cdot{ }^{13} \mathrm{C}$ NMR $\left(100 \mathrm{MHz}, \mathrm{CDCl}_{3}, 23{ }^{\circ} \mathrm{C}\right): \delta=135.62,135.60,135.57,135.54$, $133.78,133.75,129.6,127.6,125.3,106.6,89.3,62.5,62.1,37.7,26.8,23.2,21.2,19.3$, 0.1 ppm. IR: $3400,3071,2959,2857,2171,1472,1428,1250,1112,1071,843,702,615$ $\mathrm{cm}^{-1} \cdot[\alpha]_{\mathrm{D}}^{23}+10.5\left(\mathrm{c}=0.37, \mathrm{CH}_{2} \mathrm{Cl}_{2}\right)$. HRMS $(\mathrm{FAB}+) \mathrm{m} / \mathrm{z}\left([\mathrm{M}-\mathrm{H}]^{+}\right)$: Calcd for $\mathrm{C}_{28} \mathrm{H}_{40} \mathrm{O}_{2} \mathrm{Si}_{2}$ : 463.2489, Found:463.2487. 


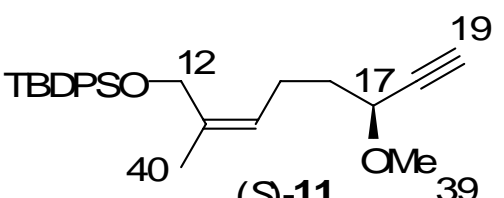

(S)-11 39

C(12)-O-TBDPS-C(17)-OMe-C(17)-(S) Intermediate of the C(12)-C(19) Subunit: (S)-11.

To a solution of propargylic alcohol $8(699 \mathrm{mg}, 1.51 \mathrm{mmol})$ in $\mathrm{PhMe}(4 \mathrm{~mL})$ at 0 ${ }^{\circ} \mathrm{C}$ was added $\mathrm{NaOH}(4 \mathrm{~mL}, 50 \mathrm{wt} \%$ aq.) followed by addition of tetrabutylammonium hydrogen sulfate $(178 \mathrm{mg}, 0.53 \mathrm{mmol})$ and dimethyl sulfate $(708 \mu \mathrm{L}, 7.50 \mathrm{mmol}) .^{7}$ The resulting two phase mixture was stirred for 5 min at $0{ }^{\circ} \mathrm{C}$, warmed to $23{ }^{\circ} \mathrm{C}$, and stirred another $3 \mathrm{~h}$. The reaction was then quenched by addition of $2 \mathrm{~mL} \mathrm{MeOH}$, followed by vigorous stirring $(10 \mathrm{~min})$. The resulting mixture was poured into water and partitioned between EtOAc and the aqueous phase. The combined organic phases were dried $\left(\mathrm{MgSO}_{4}\right)$, filtered and concentrated. Purification by flash chromatography $\left(\mathrm{SiO}_{2}, 2.8 \times 24\right.$ $\mathrm{cm}$, gradient: $4.7 \% \mathrm{EtOAc} /$ hexanes $\rightarrow 20 \% \mathrm{EtOAc} /$ hexanes) provided the desired product 11 as a clear oil $(580 \mathrm{mg}, 1.43 \mathrm{mmol}, 95 \%)\left(\mathrm{R}_{\mathrm{f}}=0.63\right.$ using $40 \%$ EtOAc/hexanes). ${ }^{1} \mathrm{H}$ NMR $\left(400 \mathrm{MHz}, \mathrm{CDCl}_{3}, 23{ }^{\circ} \mathrm{C}\right): \delta=7.73-7.64(\mathrm{~m}, 4 \mathrm{H}, \mathrm{Ph}), 7.46-$ $7.34(\mathrm{~m}, 6 \mathrm{H}, \mathrm{Ph}), 5.42$ (t, $J=7.9 \mathrm{~Hz}, 1 \mathrm{H}, \mathrm{H}_{14}, E=$ minor), 5.17 (t, $J=7.5 \mathrm{~Hz}, 1 \mathrm{H}, \mathrm{H}_{14}$, $\mathrm{Z}=$ major), 4.20 (s, $2 \mathrm{H}, \mathrm{H}_{12}, \mathrm{Z}=$ major), 4.05 (s, $2 \mathrm{H}, \mathrm{H}_{12}, E=$ minor), 3.80 (dt, $J=6.7$, $2.0 \mathrm{~Hz}, 1 \mathrm{H}, \mathrm{H}_{17}$ ), 3.33 (s, $3 \mathrm{H}, \mathrm{H}_{39}$ ), 2.32 (d, $J=2.0 \mathrm{~Hz}, 1 \mathrm{H}, \mathrm{H}_{19}$ ), 1.99 (ap. q, $2 \mathrm{H}, \mathrm{H}_{15}$ ), $1.83\left(\mathrm{~d}, J=1.2 \mathrm{~Hz}, 3 \mathrm{H}, \mathrm{H}_{40}\right), 1.73-1.56\left(\mathrm{~m}, 2 \mathrm{H}, \mathrm{H}_{16}\right), 1.05 \mathrm{ppm}\left(\mathrm{s}, 9 \mathrm{H}\right.$, tert-Butyl). ${ }^{13} \mathrm{C}$ NMR $\left(100 \mathrm{MHz}, \mathrm{CDCl}_{3}, 23{ }^{\circ} \mathrm{C}\right): \delta=135.69,135.61,133.8,129.5,127.6,125.1,82.5$, $73.8,70.3,62.5,56.4,35.6,26.8,23.2,21.2,19.3 \mathrm{ppm}$. IR: 3303, 3071, 3048, 2955, 2930, 2857, 2113, 1472, 1428, 1255, 1112, 836, $701 \mathrm{~cm}^{-1}$. $[\alpha]^{23}{ }_{\mathrm{D}}-8.8\left(\mathrm{c}=0.56, \mathrm{CH}_{2} \mathrm{Cl}_{2}\right)$. HRMS (FAB+) m/z ([M-H] $\left.]^{+}\right)$: Calcd for $\mathrm{C}_{26} \mathrm{H}_{33} \mathrm{O}_{2} \mathrm{Si}_{1}$ : 405.2250, Found: 405.2242.

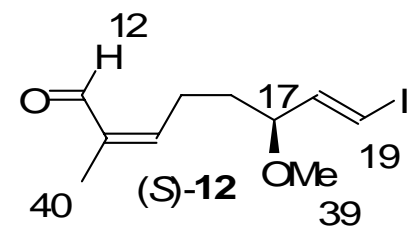

\section{Fully Functionalized C(12)-C(19) Subunit (S)-12.}

Following a literature procedure, ${ }^{8}$ alkyne $\mathbf{1 1}(335 \mathrm{mg}, 0.82 \mathrm{mmol})$ was dissolved in dry THF $(9 \mathrm{~mL})$, and solid $\mathrm{Cp}_{2} \mathrm{ZrHCl}(1.05$ eq., $224 \mathrm{mg}, 0.87 \mathrm{mmol}$, stored and weighted out in a glove box) was added at $23{ }^{\circ} \mathrm{C}$. After $30 \mathrm{~min}$, solid $\mathrm{N}$-iodo-succinimide (1.1 eq., $204 \mathrm{mg}, 0.91 \mathrm{mmol}$ ) was added. After stirring for another $60 \mathrm{~min}$ at $23{ }^{\circ} \mathrm{C}$, the mixture was diluted with $\mathrm{Et}_{2} \mathrm{O}$ and $\mathrm{EtOAc}$, and the organic phase was washed with sat. aq. $\mathrm{NaHCO}_{3}$ and brine. After drying $\left(\mathrm{MgSO}_{4}\right)$, filtering, and concentration, the remaining residue was purified by flash chromatography $\left(\mathrm{SiO}_{2}, 2.8 \times 23 \mathrm{~cm}\right.$, gradient: $4.7 \%$ EtOAc/hexanes $\rightarrow 9 \%$ EtOAc/hexanes) to provide the desired vinyl iodide as a colorless oil (422 mg, $0.79 \mathrm{mmol}, 96 \%$ yield) $\left(\mathrm{R}_{\mathrm{f}}=0.68\right.$ using $40 \%$ EtOAc/hexanes).

The TBDPS-protected vinyl iodide (128 $\mathrm{mg}, 0.239 \mathrm{mmol})$ was dissolved in THF ( $2.4 \mathrm{~mL}, 0.01 \% \mathrm{H}_{2} \mathrm{O}$ present), and $1.0 \mathrm{M} \mathrm{TBAF} / \mathrm{THF}$ (2 eq., $478 \mathrm{~mL}, 0.478 \mathrm{mmol}$ ) was added at $23{ }^{\circ} \mathrm{C}$. After $6 \mathrm{~h}$, TLC indicated complete conversion. The solution was concentrated on a rotary evaporator, and the remaining oil was applied to a flash chromatography column $\left(\mathrm{SiO}_{2}, 2.8 \times 21 \mathrm{~cm}\right.$, gradient: $4.7 \%$ EtOAc/hexanes $\rightarrow 29 \%$ 
EtOAc/hexanes) to provide the desired allylic alcohol as a colorless oil (66 mg, 0.223 mmol, $93 \%$ yield) ( $\mathrm{R}_{\mathrm{f}}=0.35$ using $40 \%$ EtOAc/hexanes).

Based upon a literature procedure, ${ }^{9}$ the allylic alcohol $(100 \mathrm{mg}, 0.34 \mathrm{mmol})$ was dissolved in $\mathrm{CH}_{2} \mathrm{Cl}_{2}(4 \mathrm{~mL})$, and freshly flame-dried molecular sieves (4 $\AA$ ) were added, followed by $N$-methyl-morpholine $N$-oxide $\quad(\mathrm{NMO}) \quad(60 \mathrm{mg}, \quad 0.51 \mathrm{mmol})$. Tetrapropylammonium perruthenate (TPAP) $(6 \mathrm{mg}, 0.02 \mathrm{mmol})$ was added $10 \mathrm{~min}$ later, and the mixture was stirred for $11 \mathrm{~h}$ at $23{ }^{\circ} \mathrm{C}$ under Ar. The mixture was diluted with $\mathrm{CH}_{2} \mathrm{Cl}_{2}$ and washed with sat. aq. $\mathrm{Na}_{2} \mathrm{SO}_{3}$ containing some brine. Following backextraction of the aqueous phase with $\mathrm{CH}_{2} \mathrm{Cl}_{2}$, the combined organic phase was dried $\left(\mathrm{MgSO}_{4}\right)$, filtered, and carefully concentrated. Purification by flask chromatography $\left(\mathrm{SiO}_{2}, 2.8 \times 20 \mathrm{~cm}\right.$, gradient: $4.7 \% \mathrm{EtOAc} /$ hexanes $\rightarrow 29 \%$ EtOAc/hexanes) provided the desired, fully functionalized C(12)-C(19) subunit (S)-12 (97 mg, $0.33 \mathrm{mmol}, 98 \%$ yield) $\left(\mathrm{R}_{\mathrm{f}}=0.43\right.$ using $40 \%$ EtOAc/hexanes) as a colorless oil. Since this allylic aldehyde is volatile under reduced pressure and susceptible to double bond isomerization, it was prepared immediately prior to use. ${ }^{1} \mathrm{H} \mathrm{NMR}\left(400 \mathrm{MHz}, \mathrm{CDCl}_{3}, 23{ }^{\circ} \mathrm{C}\right): \delta=10.13(\mathrm{~s}, 1 \mathrm{H}$, $\mathrm{H}_{12}, Z=$ major), 9.41 (s, $1 \mathrm{H}, \mathrm{H}_{12}, E=$ minor), 6.47 (t, $\left.J=8.4 \mathrm{~Hz}, 1 \mathrm{H}, \mathrm{H}_{14}\right), 6.41$ (dd, $J=$ 14.7, 7.3 Hz, $\left.1 \mathrm{H}, \mathrm{H}_{18}\right), 6.34$ (d, J = 14.6 Hz, $\left.1 \mathrm{H}, \mathrm{H}_{19}\right), 3.54\left(\mathrm{~m}, 1 \mathrm{H}, \mathrm{H}_{17}\right), 3.26(\mathrm{~s}, 3 \mathrm{H}$, $\left.\mathrm{H}_{39}\right), 2.79-2.52\left(2 \times \mathrm{m}, 2 \mathrm{H}, \mathrm{H}_{15}\right), 1.77-1.59\left(2 \times \mathrm{m}, 2 \mathrm{H}, \mathrm{H}_{16}\right), 1.55 \mathrm{ppm}\left(\mathrm{s}, 3 \mathrm{H}, \mathrm{H}_{40}\right) .{ }^{13} \mathrm{C}$ NMR $\left(100 \mathrm{MHz}, \mathrm{CDCl}_{3}, 23{ }^{\circ} \mathrm{C}\right): \delta=191.1,148.1,146.0,82.6,78.8,77.2,56.6,34.5$, 22.4, 16.5 ppm. IR: 3048, 2924, 2850, 1677, 1604, 1447, 1351, 1253, 1170, 1103, 950 $\mathrm{cm}^{-1} \cdot[\alpha]_{\mathrm{D}}^{23}+11.0\left(\mathrm{c}=0.23, \mathrm{CH}_{2} \mathrm{Cl}_{2}\right)$. HRMS $(\mathrm{FAB}+) \mathrm{m} / \mathrm{z}\left([\mathrm{M}+\mathrm{H}]^{+}\right)$: Calcd for $\mathrm{C}_{10} \mathrm{H}_{16} \mathrm{O}_{2} \mathrm{I}_{1}: 295.0195$, Found: 295.0188 .

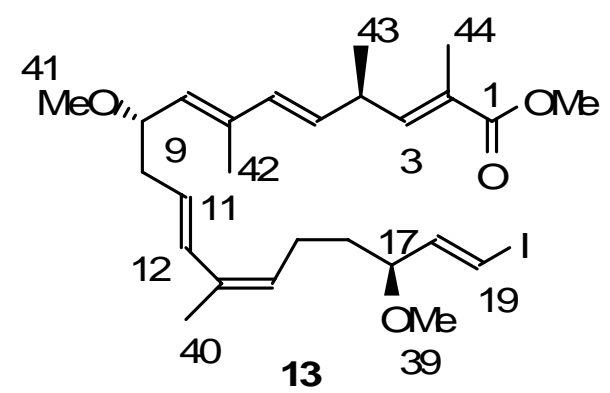

Completed C(1)-C(19) Subunit.

Following the procedure of LaFontaine, ${ }^{1} \mathrm{C}(1)-\mathrm{C}(11)$ sulfone $4(51 \mathrm{mg}, 0.113$ mmol) and $\mathrm{C}(12)-\mathrm{C}(19)$ aldehyde $(S)-12(32 \mathrm{mg}, 0.113 \mathrm{mmol})$ were combined in the same flask and dissolved in THF $(4.4 \mathrm{~mL})$. The solution was cooled to $-78{ }^{\circ} \mathrm{C}$ and LiHMDS $(0.34 \mathrm{~mL}, 1.0 \mathrm{M}$ in THF, $0.34 \mathrm{mmol})$ was added dropwise. After stirring for $2 \mathrm{~h}$ at $-78{ }^{\circ} \mathrm{C}$, the cold bath was removed and the solution was allowed to warm to $23{ }^{\circ} \mathrm{C}$ over a time period of $30 \mathrm{~min}$. It was quenched with sat. aq. $\mathrm{NH}_{4} \mathrm{Cl}$ and extracted with $\mathrm{CH}_{2} \mathrm{Cl}_{2}$ $(3 \times)$. The combined organic phase was dried $\left(\mathrm{MgSO}_{4}\right)$, filtered, and concentrated. Purification by flask chromatography (first column: $\mathrm{SiO}_{2}, 2.8 \times 25 \mathrm{~cm}$, gradient: $4.7 \%$ EtOAc/hexanes $\rightarrow 17 \%$ EtOAc/hexanes; second column: $\mathrm{SiO}_{2}, 2.8 \times 20 \mathrm{~cm}$, gradient: $4.7 \%$ EtOAc/hexanes $\rightarrow 13 \%$ EtOAc/hexanes) provided the methyl ester of the $\mathrm{C}(1)$ $\mathrm{C}(19)$ subunit (13) $\left(35 \mathrm{mg}, 0.065 \mathrm{mmol}, 57 \%\right.$ yield) $\left(\mathrm{R}_{\mathrm{f}}=0.62\right.$ using $40 \%$ EtOAc/hexanes) as a colorless oil. ${ }^{1} \mathrm{H}$ NMR $\left(400 \mathrm{MHz}, \mathrm{CDCl}_{3}, 23{ }^{\circ} \mathrm{C}\right): \delta=6.61(\mathrm{dq}, J=$ 9.8, $\left.1.4 \mathrm{~Hz}, 1 \mathrm{H}, \mathrm{H}_{3}\right), 6.44\left(\mathrm{~d}, J=15.6 \mathrm{~Hz}, 1 \mathrm{H}, \mathrm{H}_{12}\right), 6.39(\mathrm{dd}, J=14.5,7.7 \mathrm{~Hz}, 1 \mathrm{H}$, $\left.\mathrm{H}_{18}\right), 6.27\left(\mathrm{~d}, J=14.6 \mathrm{~Hz}, 1 \mathrm{H}, \mathrm{H}_{19}\right), 6.08\left(\mathrm{~d}, J=15.7 \mathrm{~Hz}, 1 \mathrm{H}, \mathrm{H}_{6}\right), 5.61\left(\mathrm{~m}, 2 \mathrm{H}, \mathrm{H}_{5}\right.$, 
$\left.\mathrm{H}_{11}\right), 5.29\left(\mathrm{~d}, J=9.2 \mathrm{~Hz}, 1 \mathrm{H}, \mathrm{H}_{8}\right), 5.20\left(\mathrm{t}, J=7.6 \mathrm{~Hz}, 1 \mathrm{H}, \mathrm{H}_{14}\right), 4.05\left(\mathrm{~m}, 1 \mathrm{H}, \mathrm{H}_{9}\right), 3.74$ (s, $\left.3 \mathrm{H}, \mathrm{CO}_{2} \mathrm{CH}_{3}\right), 3.49\left(\mathrm{~m}, 1 \mathrm{H}, \mathrm{H}_{17}\right), 3.25\left(\mathrm{~s}, 6 \mathrm{H}, \mathrm{H}_{39}, \mathrm{H}_{41}\right), 3.25\left(\mathrm{~m}, 1 \mathrm{H}, \mathrm{H}_{4}\right), 2.50-2.05$ $\left(\mathrm{m}, 4 \mathrm{H}, \mathrm{H}_{10}, \mathrm{H}_{15}\right), 1.87\left(\mathrm{~d}, J=1.5 \mathrm{~Hz}, 3 \mathrm{H}, \mathrm{H}_{40}, \mathrm{H}_{42}\right.$, or $\left.\mathrm{H}_{44}\right), 1.78(\mathrm{~d}, J=1.1 \mathrm{~Hz}, 3 \mathrm{H}$, $\mathrm{H}_{40}, \mathrm{H}_{42}$, or $\left.\mathrm{H}_{44}\right), 1.77$ (d, $J=1.2 \mathrm{~Hz}, 3 \mathrm{H}, \mathrm{H}_{40}, \mathrm{H}_{42}$, or $\left.\mathrm{H}_{44}\right), 1.63\left(\mathrm{~m}, 1 \mathrm{H}, \mathrm{H}_{16}\right), 1.51$ (m, $\left.1 \mathrm{H}, \mathrm{H}_{16}\right), 1.16 \mathrm{ppm}\left(\mathrm{d}, J=6.8 \mathrm{~Hz}, 3 \mathrm{H}, \mathrm{H}_{43}\right) .{ }^{13} \mathrm{C} \mathrm{NMR}\left(125 \mathrm{MHz}, \mathrm{CDCl}_{3}, 23{ }^{\circ} \mathrm{C}\right): \delta=$ 169.0, 146.8, 145.4, 136.6, 133.7, 132.9, 131.9, 131.5, 129.4, 128.2, 126.4, 83.3, 78.5, $77.5,56.8,56.3,52.0,39.7,36.5,35.0,24.2,23.1,20.9,20.5,13.3,12.8$ ppm. IR: 2960, $2927,1715,1647,1606,1435,1261,1099,1018,965,873,800,750 \mathrm{~cm}^{-1} \cdot[\alpha]^{23}+2.4(\mathrm{c}$ $\left.=0.00208, \mathrm{CHCl}_{3}\right)$. HRMS $(\mathrm{FAB}+) \mathrm{m} / \mathrm{z}\left([\mathrm{M}-\mathrm{H}]^{+}\right)$: Calcd for $\mathrm{C}_{26} \mathrm{H}_{38} \mathrm{IO}_{4}:$ 541.1815, Found: 541.1838 .

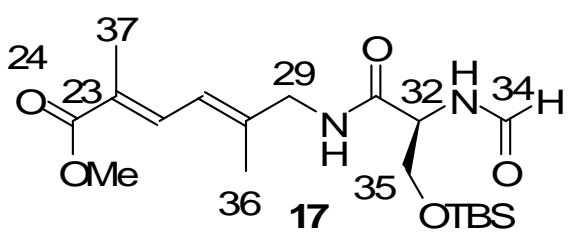

\section{$O$-TBS-protected Iejimalide Side Chain (17).}

Fresh, dry $\mathrm{CH}_{2} \mathrm{Cl}_{2}(7.5 \mathrm{~mL})$ was added to a flask containing diene-amine 16 (135 $\mathrm{mg}, 0.80 \mathrm{mmol}$ ) and $N$-formyl- $O$-TBS-(S)-serine (15) $(180 \mathrm{mg}, 0.73 \mathrm{mmol})$. Under Ar, the suspension was cooled to $0{ }^{\circ} \mathrm{C}$ and diethylcyanophosphonate (diethylphosphoryl cyanide, DEPC, $125 \mu \mathrm{L}, 0.82 \mathrm{mmol})$ followed by $\mathrm{CaH}_{2}$-distilled $\mathrm{NEt}_{3}(125 \mu \mathrm{L}, 0.92$ mmol) were added dropwise. Serine derivative 15 dissolved upon the addition of $\mathrm{NEt}_{3}$. The solution was stirred overnight, during which time it was allowed to warmed to $23{ }^{\circ} \mathrm{C}$. The reaction mixture was directly applied to a flash chromatography column $\left(\mathrm{SiO}_{2}, 2.8 \mathrm{x}\right.$ $13.5 \mathrm{~cm}$, gradient: $100 \% \mathrm{CH}_{2} \mathrm{Cl}_{2} \rightarrow 7.4 \% \mathrm{MeOH} / \mathrm{CH}_{2} \mathrm{Cl}_{2}$ ) for purification. Thereafter, another column $\left[\left(\mathrm{SiO}_{2}, 2.8 \times 17 \mathrm{~cm}\right.\right.$, gradient: $100 \%$ hexanes $\rightarrow 29 \% \mathrm{EtOAc} /$ hexanes $)$ or $\left(\mathrm{SiO}_{2}, 2.8 \times 20 \mathrm{~cm}\right.$, prepared with $\mathrm{CH}_{2} \mathrm{Cl}_{2}$, gradient: 100/40/1 hexanes/EtOAc/ $\mathrm{MeOH} \rightarrow$ $100 / 40 / 8$ hexanes/EtOAc/MeOH)] was necessary to obtain clean product $17(232 \mathrm{mg}$, $0.58 \mathrm{mmol}, 80 \%$ yield) $\left(\mathrm{R}_{\mathrm{f}}=0.46\right.$ using $10 / 1 \mathrm{CH}_{2} \mathrm{Cl}_{2} / \mathrm{MeOH} \& \mathrm{R}_{\mathrm{f}}=0.34$ using $100 \%$ EtOAc). ${ }^{1} \mathrm{H}$ NMR ( $\left(300 \mathrm{MHz}, \mathrm{CDCl}_{3}, 23{ }^{\circ} \mathrm{C}\right): \delta=8.22\left(\mathrm{~s}, 1 \mathrm{H}, \mathrm{H}_{34}\right), 7.38(\mathrm{~d}, J=11.8 \mathrm{~Hz}$, $\left.1 \mathrm{H}, \mathrm{H}_{25}\right), 6.87(\mathrm{~m}, 2 \mathrm{H}, 2 \times \mathrm{NH}), 6.20\left(\mathrm{~d}, J=11.8 \mathrm{~Hz}, 1 \mathrm{H}, \mathrm{H}_{26}\right), 4.51\left(\mathrm{~m}, 1 \mathrm{H}, \mathrm{H}_{32}\right), 4.03$ (dd, $\left.J=9.8,4.2 \mathrm{~Hz}, 1 \mathrm{H}, \mathrm{H}_{35}\right), 3.93\left(\mathrm{~m}, 2 \mathrm{H}, \mathrm{H}_{29}\right), 3.73$ (s, $\left.3 \mathrm{H}, \mathrm{OCH}_{3}\right), 3.62$ (dd, $J=9.7$, $\left.8.0 \mathrm{~Hz}, 1 \mathrm{H}, \mathrm{H}_{35^{\prime}}\right), 1.90\left(\mathrm{~s}, 3 \mathrm{H},=\mathrm{CCH}_{3}\right), 1.84\left(\mathrm{~s}, 3 \mathrm{H},=\mathrm{C}^{-\mathrm{CH}_{3}}\right), 0.85$ (s, $9 \mathrm{H}$, tert-Butyl), $0.07\left(\mathrm{~s}, 3 \mathrm{H}, \mathrm{Si}\left(\mathrm{CH}_{3}\right)_{2}\right), 0.05 \mathrm{ppm}\left(\mathrm{s}, 3 \mathrm{H}, \mathrm{Si}\left(\mathrm{CH}_{3}\right)_{2}\right) .{ }^{13} \mathrm{C} \mathrm{NMR}\left(125 \mathrm{MHz}, \mathrm{CDCl}_{3}, 23\right.$ $\left.{ }^{\circ} \mathrm{C}\right): \delta=170.0,169.3,161.3,142.2,133.5,127.2,121.6,62.7,53.2,52.1,47.3,26.0,18.3$, $15.8,12.9,-5.2,-5.3 \mathrm{ppm}$. IR: $3275,2953,2931,1708,1666,1641 \mathrm{~cm}^{-1} \cdot[\alpha]^{23}+7.9(\mathrm{c}=$ 0.0014, $\left.\mathrm{CHCl}_{3}\right)$. Mp: $112{ }^{\circ} \mathrm{C}$. HRMS (FAB+) $\mathrm{m} / \mathrm{z}\left([\mathrm{M}+\mathrm{H}]^{+}\right)$: Calcd for $\mathrm{C}_{19} \mathrm{H}_{35} \mathrm{~N}_{2} \mathrm{O}_{5} \mathrm{Si}$ : 399.2315, Found: 399.2289 . 


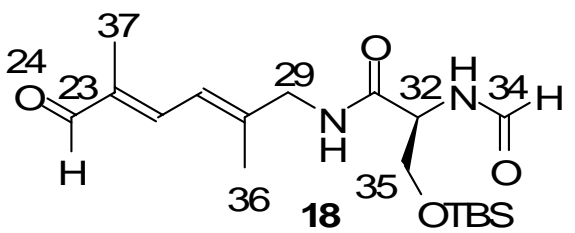

\section{Iejimalide Side Chain Aldehyde 18.}

A solution of $O$-TBS protected iejimalide side chain ester $17(630 \mathrm{mg}, 1.58$ mmol) in $\mathrm{CH}_{2} \mathrm{Cl}_{2}(14 \mathrm{~mL})$ was cooled to $-78{ }^{\circ} \mathrm{C}$ and DIBAL-H $(4.74 \mathrm{~mL}, 1.0 \mathrm{M}$ in hexanes, $4.74 \mathrm{mmol}, 3.0$ equiv) was added dropwise. After $3 \mathrm{~h}$ at $-78^{\circ} \mathrm{C}$, the reaction was quenched at $-78{ }^{\circ} \mathrm{C}$ with $\mathrm{MeOH}(30 \mathrm{~mL})$, and 10 min later the cold bath was removed. Once the mixture was at about $0{ }^{\circ} \mathrm{C}$, a sat. aq. Rochelle's salt solution was added, and the mixture was vigorously stirred over night. It was extracted with $\mathrm{CH}_{2} \mathrm{Cl}_{2}(4 \times)$, and the combined organic phase was dried $\left(\mathrm{MgSO}_{4}\right)$, filtered, and evaporated to dryness. Flash chromatography $\left(\mathrm{SiO}_{2}, 2.8 \times 16.5 \mathrm{~cm}\right.$, gradient: $\left.100 \% \mathrm{CH}_{2} \mathrm{Cl}_{2} \rightarrow 6 \% \mathrm{MeOH} / \mathrm{CH}_{2} \mathrm{Cl}_{2}\right)$ of the residue provided the intermediate alcohol $(345 \mathrm{mg}, 0.93 \mathrm{mmol}, 59 \%$ yield $\& 82 \%$ yield based on recovered starting material) $\left(\mathrm{R}_{\mathrm{f}}=0.37\right.$ using $\left.10 / 1 \mathrm{CH}_{2} \mathrm{Cl}_{2} / \mathrm{MeOH}\right)$.

The intermediate alcohol $(345 \mathrm{mg}, 0.93 \mathrm{mmol})$ was dissolved in normal non-dried $\mathrm{CH}_{2} \mathrm{Cl}_{2}\left(9.3 \mathrm{~mL}\right.$ ), cooled to $0{ }^{\circ} \mathrm{C}$, and Dess-Martin periodinane (474 $\mathrm{mg}, 1.12 \mathrm{mmol}, 1.2$ equiv) was added in one portion. After stirring for $15 \mathrm{~min}$ at $0{ }^{\circ} \mathrm{C}$, the solution was allowed to stir for $45 \mathrm{~min}$ at $23{ }^{\circ} \mathrm{C}$, after which it was quenched with an aq. basic $\mathrm{Na}_{2} \mathrm{~S}_{2} \mathrm{O}_{3}$ solution $\left(17 \mathrm{~mL}\right.$ of a solution prepared by dissolving $25 \mathrm{~g} \mathrm{Na}_{2} \mathrm{~S}_{2} \mathrm{O}_{3}$ in $100 \mathrm{~mL}$ of sat. aq. $\mathrm{NaHCO}_{3}$ ). The resulting mixture was vigorously stirred for $15 \mathrm{~min}$ and then extracted with $\mathrm{CH}_{2} \mathrm{Cl}_{2}(3 \times)$. After drying $\left(\mathrm{MgSO}_{4}\right)$, filtration, and concentration, the remaining residue was purified by flash chromatography $\left(\mathrm{SiO}_{2}, 2.8 \times 26 \mathrm{~cm}\right.$, prepared with $\mathrm{CH}_{2} \mathrm{Cl}_{2}$, gradient: $100 \% \mathrm{CH}_{2} \mathrm{Cl}_{2} \rightarrow 3.8 \% \mathrm{MeOH} / \mathrm{CH}_{2} \mathrm{Cl}_{2}$ ) to give the desired aldehyde 18 (329 mg, $0.89 \mathrm{mmol}, 96 \%$ yield) $\left(\mathrm{R}_{\mathrm{f}}=0.45\right.$ using $\left.10 / 1 \mathrm{CH}_{2} \mathrm{Cl}_{2} / \mathrm{MeOH}\right)$ as an off-white solid. ${ }^{1} \mathrm{H}$ NMR $\left(500 \mathrm{MHz}, \mathrm{CDCl}_{3}, 23{ }^{\circ} \mathrm{C}\right): \delta=9.46\left(\mathrm{~s}, 1 \mathrm{H}, \mathrm{H}_{23}\right), 8.26(\mathrm{~s}, 1 \mathrm{H}$, $\left.\mathrm{H}_{34}\right), 7.06\left(\mathrm{~d}, J=11.6 \mathrm{~Hz}, 1 \mathrm{H}, \mathrm{H}_{25}\right), 6.87$ (t, $\left.J=5.9 \mathrm{~Hz}, 1 \mathrm{H}, \mathrm{N}_{30} \mathrm{H}\right), 6.70(\mathrm{~d}, J=6.4 \mathrm{~Hz}$, $\left.1 \mathrm{H}, \mathrm{N}_{33} \mathrm{H}\right), 6.41\left(\mathrm{~d}, J=11.6 \mathrm{~Hz}, 1 \mathrm{H}, \mathrm{H}_{26}\right), 4.51\left(\mathrm{~m}, 1 \mathrm{H}, \mathrm{H}_{32}\right), 4.08$ (dd, $J=9.8,4.1 \mathrm{~Hz}$, $\left.1 \mathrm{H}, \mathrm{H}_{35}\right), 4.00\left(\mathrm{~m}, 2 \mathrm{H}, \mathrm{H}_{29}\right), 3.63$ (dd, $\left.J=9.8,7.9 \mathrm{~Hz}, 1 \mathrm{H}, \mathrm{H}_{35^{\prime}}\right), 1.92\left(\mathrm{~s}, 3 \mathrm{H},=\mathrm{CCH}_{3}\right)$, $1.82\left(\mathrm{~s}, 3 \mathrm{H},=\mathrm{C}-\mathrm{CH}_{3}\right), 0.86\left(\mathrm{~s}, 9 \mathrm{H}\right.$, tert-Butyl), 0.10 (s, $\left.3 \mathrm{H}, \mathrm{Si}\left(\mathrm{CH}_{3}\right)_{2}\right), 0.07 \mathrm{ppm}(\mathrm{s}, 3 \mathrm{H}$, $\left.\mathrm{Si}\left(\mathrm{CH}_{3}\right)_{2}\right) .{ }^{13} \mathrm{C} \mathrm{NMR}\left(125 \mathrm{MHz}, \mathrm{CDCl}_{3}, 23{ }^{\circ} \mathrm{C}\right): \delta=195.3,170.0,161.3,145.1,143.6$, 137.8, 121.1, 62.7, 53.2, 47.1, 25.9, 18.2, 15.9, 9.6, -5.3, -5.4 ppm. IR: 3276, 2951, 2930, 2860, 1665, 1646, 1561, 1385, 1229, 1127, $839 \mathrm{~cm}^{-1} .[\alpha]^{23}+10.4\left(\mathrm{c}=0.0142, \mathrm{CHCl}_{3}\right)$. Mp: $110{ }^{\circ} \mathrm{C}$. HRMS $(\mathrm{FAB}+) \mathrm{m} / \mathrm{z}\left([\mathrm{M}+\mathrm{H}]^{+}\right)$: Calcd for $\mathrm{C}_{18} \mathrm{H}_{33} \mathrm{~N}_{2} \mathrm{O}_{4} \mathrm{Si}$ : 369.2210, Found: 369.2231 .

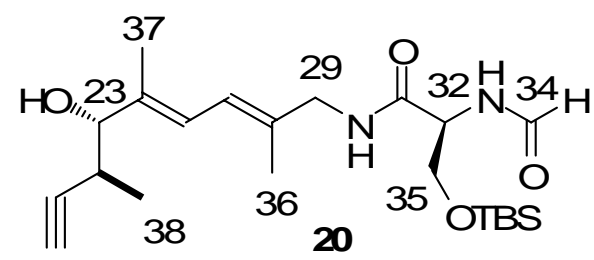

20

C(20)-C(34) Alkyne 20.

$\mathrm{C}(23)-\mathrm{C}(34)$ aldehyde 18 (84 $\mathrm{mg}, 0.228 \mathrm{mmol})$ and $\mathrm{PPh}_{3}(3.6 \mathrm{mg}, 0.014 \mathrm{mmol})$ were dissolved in THF $(2 \mathrm{~mL})$ and HMPA $(0.5 \mathrm{~mL})$. (R)-4-TMS-3-butyn-2-yl 
methanesulfonate $^{10}(57 \mu \mathrm{L}, 0.274 \mathrm{mmol}, \rho=1.057 \mathrm{~g} / \mathrm{mL})$ was added, and the solution was put into a preheated oil bath with a temperature of $55^{\circ} \mathrm{C} . \operatorname{Pd}(\mathrm{OAc})_{2}(3.1 \mathrm{mg}, 0.014$ mmol) was added, followed by powdered InI $(66 \mathrm{mg}, 0.274 \mathrm{mmol})$ exactly one minute later. ${ }^{11}$ After stirring for 4 hours at $55^{\circ} \mathrm{C}$ under Ar, the flask was removed from the oil bath. Once the content was cooled to $23{ }^{\circ} \mathrm{C}$, it was poured into sat. aq. $\mathrm{NH}_{4} \mathrm{Cl}$ in a separation funnel, and extracted with $\mathrm{CH}_{2} \mathrm{Cl}_{2}(3 \times)$. The combined organic phase was dried $\left(\mathrm{MgSO}_{4}\right)$, filtered, and concentrated. The residue was purified by flash chromatography $\left[\left(\mathrm{SiO}_{2}, 2.8 \times 23.5 \mathrm{~cm}\right.\right.$, prepared with $\mathrm{CH}_{2} \mathrm{Cl}_{2}$, gradient: $100 \% \mathrm{CH}_{2} \mathrm{Cl}_{2} \rightarrow$ $\left.4.8 \% \mathrm{MeOH} / \mathrm{CH}_{2} \mathrm{Cl}_{2}\right)$ and $\left(\mathrm{SiO}_{2}, 2.8 \times 17 \mathrm{~cm}\right.$, prepared with $\mathrm{CH}_{2} \mathrm{Cl}_{2}$, gradient: $100 \%$ $\left.\mathrm{CH}_{2} \mathrm{Cl}_{2} \rightarrow 2.0 \% \mathrm{MeOH} / \mathrm{CH}_{2} \mathrm{Cl}_{2}\right)$ ] to provide the intermediate TMS-alkyne $\left(\mathrm{R}_{\mathrm{f}}=0.54\right.$ using $10 / 1 \mathrm{CH}_{2} \mathrm{Cl}_{2} / \mathrm{MeOH}$ ) contaminated with some HMPA.

HMPA-contaminated intermediate TMS-alkyne was dissolved in $\mathrm{MeOH}(4.3 \mathrm{~mL})$ and $\mathrm{K}_{2} \mathrm{CO}_{3}\left(56 \mathrm{mg}, 0.405 \mathrm{mmol}\right.$ ) was added. After vigorous stirring for $6 \mathrm{~h}$ at $23{ }^{\circ} \mathrm{C}$, the mixture was poured into sat. aq. $\mathrm{NH}_{4} \mathrm{Cl}$ in a separation funnel, and extracted with $\mathrm{CH}_{2} \mathrm{Cl}_{2}$ $(3 \times)$. The combined organic phase was dried $\left(\mathrm{MgSO}_{4}\right)$, filtered, and evaporated to dryness. Flash chromatography $\left[\left(\mathrm{SiO}_{2}, 2.8 \times 18 \mathrm{~cm}\right.\right.$, prepared with $\mathrm{CH}_{2} \mathrm{Cl}_{2}$, gradient: $\left.100 \% \mathrm{CH}_{2} \mathrm{Cl}_{2} \rightarrow 4.7 \% \mathrm{MeOH} / \mathrm{CH}_{2} \mathrm{Cl}_{2}\right)$ and $\left(\mathrm{SiO}_{2}, 2.8 \times 17 \mathrm{~cm}\right.$, prepared with $\mathrm{CH}_{2} \mathrm{Cl}_{2}$, gradient: $100 \% \mathrm{CH}_{2} \mathrm{Cl}_{2} \rightarrow 3.8 \% \mathrm{MeOH} / \mathrm{CH}_{2} \mathrm{Cl}_{2}$ )] provided the desired $\mathrm{C}(20)-\mathrm{C}(34)$ alkyne 20 (75 mg, $0.177 \mathrm{mmol}, 78 \%$ yield) $\left(\mathrm{R}_{\mathrm{f}}=0.53\right.$ using $\left.10 / 1 \mathrm{CH}_{2} \mathrm{Cl}_{2} / \mathrm{MeOH}\right)$ as a nearly colorless oil. Ratio of diastereomers of this batch: 4.97/1. ${ }^{1} \mathrm{H}$ NMR (400 MHz, $\mathrm{CDCl}_{3}, 23{ }^{\circ} \mathrm{C}$ ): $\delta=8.26\left(\mathrm{~s}, 1 \mathrm{H}, \mathrm{H}_{34}\right), 6.59$ (br s, $\left.2 \mathrm{H}, \mathrm{N}_{30} \mathrm{H} \& \mathrm{~N}_{33} \mathrm{H}\right), 6.23(\mathrm{~d}, J=11.1$ $\left.\mathrm{Hz}, 1 \mathrm{H}, \mathrm{H}_{25}\right), 6.15$ (d, $\left.J=11.1 \mathrm{~Hz}, 1 \mathrm{H}, \mathrm{H}_{26}\right), 4.46$ (m, $\left.1 \mathrm{H}, \mathrm{H}_{32}\right), 4.09$ (dd, $J=9.7,4.1$ $\left.\mathrm{Hz}, 1 \mathrm{H}, \mathrm{H}_{35}\right), 3.91\left(\mathrm{~m}, 3 \mathrm{H}, \mathrm{H}_{23}, \mathrm{H}_{29}\right), 3.58$ (dd, $\left.J=9.7,8.3 \mathrm{~Hz}, 1 \mathrm{H}, \mathrm{H}_{35^{\prime}}\right), 2.69$ (m, $1 \mathrm{H}$, $\mathrm{H}_{22}$ ), $2.22(\mathrm{~d}, J=3.6 \mathrm{~Hz}, 1 \mathrm{H}, \mathrm{OH}), 2.17\left(\mathrm{~d}, J=2.4 \mathrm{~Hz}, 1 \mathrm{H}, \mathrm{H}_{20}\right), 1.76\left(\mathrm{~s}, 3 \mathrm{H},=\mathrm{CCH}_{3}\right)$, $1.73\left(\mathrm{~s}, 3 \mathrm{H},=\mathrm{C}-\mathrm{CH}_{3}\right), 1.12\left(\mathrm{~d}, J=7.0 \mathrm{~Hz}, 3 \mathrm{H}, \mathrm{H}_{38}\right), 0.88(\mathrm{~s}, 9 \mathrm{H}$, tert-Butyl), $0.11(\mathrm{~s}, 3$ $\left.\mathrm{H}, \mathrm{Si}\left(\mathrm{CH}_{3}\right)_{2}\right), 0.08 \mathrm{ppm}\left(\mathrm{s}, 3 \mathrm{H}, \mathrm{Si}\left(\mathrm{CH}_{3}\right)_{2}\right) .{ }^{13} \mathrm{C} \mathrm{NMR}\left(100 \mathrm{MHz}, \mathrm{CDCl}_{3}, 23{ }^{\circ} \mathrm{C}\right): \delta=$ $169.8,161.2$, 136.8, 134.6, 123.5, 122.2, 85.8, 81.1, 71.1, 62.7, 53.1, 47.5, 31.5, 26.0, 18.3, 17.8, 15.2, 12.0, -5.3, -5.4 ppm. IR: 3307, 2929, 2857, 2112, 1659, 1550, 1462 , $1388,1254,1112,1028,837 \mathrm{~cm}^{-1} .[\alpha]_{\mathrm{D}}^{23}+24.5\left(\mathrm{c}=0.0022, \mathrm{CHCl}_{3}\right)$. HRMS $(\mathrm{FAB}+) \mathrm{m} / \mathrm{z}$ $\left([\mathrm{M}+\mathrm{H}]^{+}\right)$: Calcd for $\mathrm{C}_{22} \mathrm{H}_{39} \mathrm{~N}_{2} \mathrm{O}_{4} \mathrm{Si}: 423.2679$, Found: 423.2629 .

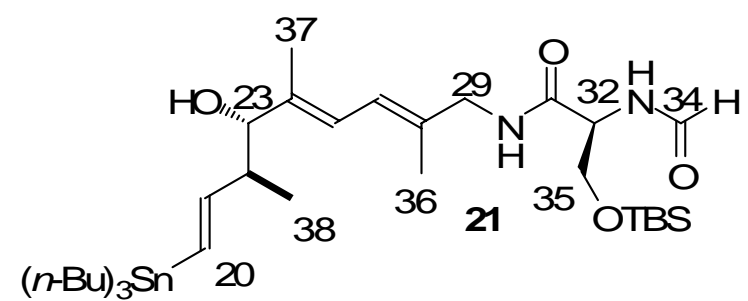

(C20)-C(34) Vinyl Stannane 21.

C(20)-C(34) alkyne 20 (148 $\mathrm{mg}, 0.35 \mathrm{mmol})$ was dissolved in THF (3.5 mL), $\mathrm{Pd}(\mathrm{dppf}) \mathrm{Cl}_{2} \times \mathrm{CH}_{2} \mathrm{Cl}_{2}$ (14 mg, $0.018 \mathrm{mmol}, 0.05$ equiv) was added, and at $23{ }^{\circ} \mathrm{C} \mathrm{HSn}(n-$ $\mathrm{Bu})_{3}(0.377 \mathrm{~mL}, 1.4 \mathrm{mmol}, 4$ equiv) was added dropwise over $20 \mathrm{~min}$. After completed addition, the solution was stirred for another $30 \mathrm{~min}$ at $23{ }^{\circ} \mathrm{C}$ and then concentrated on a rotary evaporator. An ${ }^{1} \mathrm{H}$ NMR of the crude product indicated a 16/1 E/gem isomer ratio. All of the gem isomer $\left(\mathrm{R}_{\mathrm{f}}=0.51\right.$ using $\left.9 / 1 \mathrm{CH}_{2} \mathrm{Cl}_{2} / \mathrm{MeOH}\right)$ could be separated during the following chromatographic purification. The concentrated reaction mixture was directly applied to a flash chromatography column $\left(\mathrm{SiO}_{2}, 2.8 \times 27 \mathrm{~cm}\right.$, isocratic: $1 \%$ 
$\mathrm{NEt}_{3} / \mathrm{CH}_{2} \mathrm{Cl}_{2}$ ). The combined product was evaporated in vacuum, dissolved in dry EtOAc, filtered through cotton in a pipette, and evaporated in vacuum to provide the desired C(20)-C(34) vinyl stannane 21 (217 mg, 0.30 mmol, 87\% yield) ( $\mathrm{R}_{\mathrm{f}}=0.61 \mathrm{using}$ $\left.9 / 1 \mathrm{CH}_{2} \mathrm{Cl}_{2} / \mathrm{MeOH}\right)$ as an oil. The material undergoes partial decomposition during silica gel chromatography; fortunately, the presence of $\mathrm{NEt}_{3}$ in the eluent was found to stabilize it. The peaks at 3.3, 5.1 and $5.3 \mathrm{ppm}$ in the ${ }^{1} \mathrm{H}$ NMR spectrum are due to trace amounts of $\mathrm{CH}_{2} \mathrm{Cl}_{2}$ and $\mathrm{NEt}_{3}$ adsorbed onto colloidal $\mathrm{SiO}_{2}$ which could not be separated from the material after the completion of the chromatographic purification. This specific sample also contained inseparable trace amounts of $\mathrm{PPh}_{3} .{ }^{1} \mathrm{H}$ NMR $\left(400 \mathrm{MHz}, \mathrm{CDCl}_{3}, 23{ }^{\circ} \mathrm{C}\right): \delta$ $=8.26\left(\mathrm{~s}, 1 \mathrm{H}, \mathrm{H}_{34}\right), 6.58\left(\mathrm{br} \mathrm{s}, 2 \mathrm{H}, \mathrm{N}_{30} \mathrm{H} \& \mathrm{~N}_{33} \mathrm{H}\right), 6.16\left(\mathrm{~m}, 3 \mathrm{H}, \mathrm{H}_{20}, \mathrm{H}_{25}, \mathrm{H}_{26}\right), 5.82$ (dd, $\left.J=19.0,8.0 \mathrm{~Hz}, 1 \mathrm{H}, \mathrm{H}_{21}\right), 4.46\left(\mathrm{~m}, 1 \mathrm{H}, \mathrm{H}_{32}\right), 4.10$ (dd, $\left.J=9.6,4.1 \mathrm{~Hz}, 1 \mathrm{H}, \mathrm{H}_{35}\right)$, $3.92\left(\mathrm{~m}, 2 \mathrm{H}, \mathrm{H}_{29}\right), 3.70\left(\mathrm{~d}, J=8.9 \mathrm{~Hz}, 1 \mathrm{H}, \mathrm{H}_{23}\right), 3.58\left(\mathrm{dd}, J=9.7,8.4 \mathrm{~Hz}, 1 \mathrm{H}, \mathrm{H}_{35^{\prime}}\right.$ ), $2.34\left(\mathrm{~m}, 1 \mathrm{H}, \mathrm{H}_{22}\right), 1.74\left(\mathrm{~d}, J=3.2 \mathrm{~Hz}, 3 \mathrm{H},=\mathrm{CCH}_{3}\right), 1.58\left(\mathrm{~s}, 3 \mathrm{H},=\mathrm{C}_{-} \mathrm{CH}_{3}\right), 1.49(\mathrm{~m}, 6$ $\mathrm{H}, n-\mathrm{Bu}), 1.31(\mathrm{~m}, 6 \mathrm{H}, n-\mathrm{Bu}), 0.89\left(\mathrm{~m}, 27 \mathrm{H}\right.$, tert-Butyl, $\left.\mathrm{H}_{38}, n-\mathrm{Bu}\right), 0.12(\mathrm{~s}, 3 \mathrm{H}$, $\left.\mathrm{Si}\left(\mathrm{CH}_{3}\right)_{2}\right), 0.08 \mathrm{ppm}\left(\mathrm{s}, 3 \mathrm{H}, \mathrm{Si}\left(\mathrm{CH}_{3}\right)_{2}\right) .{ }^{13} \mathrm{C} \mathrm{NMR}\left(125 \mathrm{MHz}, \mathrm{CDCl}_{3}, 23{ }^{\circ} \mathrm{C}, \mathrm{PPh}_{3}\right.$ peaks not listed): $\delta=169.8,161.2,151.3,132.4,132.3,131.8,123.3,122.6,81.1,62.7,53.1$, 47.6, 46.9, 29.9, 29.5, 29.3, 27.7, 27.5, 26.0, 18.3, 17.0, 15.2, 13.9, 11.9, 10.7, 9.7, 8.1, 5.2, -5.3 ppm. IR: 3297, 2956, 2855, 1652, 1556, 1464, 1386, 1258, 1108, 1006, 838, 779 $\mathrm{cm}^{-1} \cdot[\alpha]^{23}+16.8\left(\mathrm{c}=0.00352, \mathrm{CHCl}_{3}\right)$. HRMS $(\mathrm{FAB}+) \mathrm{m} / \mathrm{z}\left([\mathrm{M}-\mathrm{OH}]^{+}\right):$Calcd for $\mathrm{C}_{34} \mathrm{H}_{65} \mathrm{~N}_{2} \mathrm{O}_{3} \mathrm{SiSn}$ : 697.3793, Found: 697.3776.

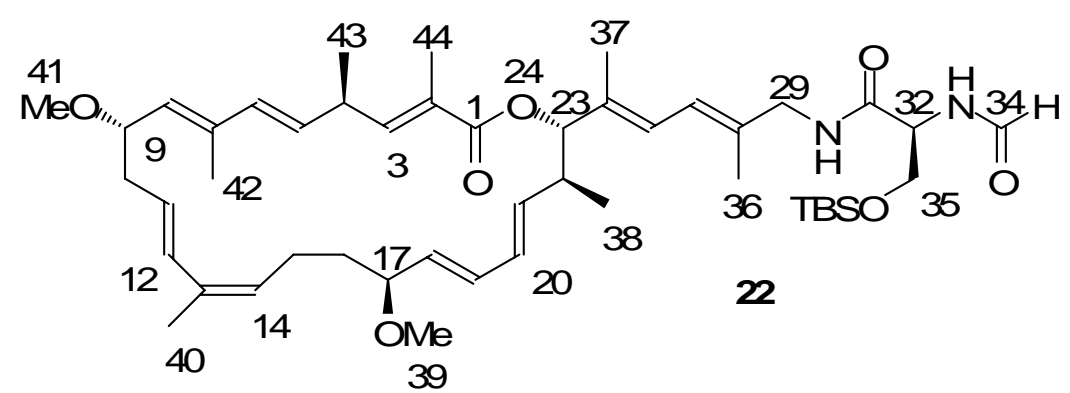

O-TBS-protected Iejimalide B (22).

\section{(A) Stille Coupling. ${ }^{12}$}

Immediately prior to use, the methyl ester of the C(1)-C(19) subunit (13) (39 mg, $0.072 \mathrm{mmol})$ was suspended in a $\mathrm{LiOH}$ solution $\left(0.1 \mathrm{M} \mathrm{LiOH}\right.$ in $1.2 / 1 \mathrm{i}-\mathrm{PrOH} / \mathrm{H}_{2} \mathrm{O}, 10$ equiv, $0.72 \mathrm{mmol}, 7.2 \mathrm{~mL}$ ) and the mixture was stirred at $23{ }^{\circ} \mathrm{C}$ for a period of $10 \mathrm{~h}$. The reaction was neutralized with aq. $\mathrm{NaHSO}_{4}(1.04$ eq., $0.15 \mathrm{M})$, diluted with EtOAc, and extracted with sat. aq. $\mathrm{NaCl}(2 \times 7.5 \mathrm{~mL})$. After drying $\left(\mathrm{MgSO}_{4}\right)$, filtering, and evaporation to dryness under vacuum, a ${ }^{1} \mathrm{H}$ NMR of the crude product $(38 \mathrm{mg}, 0.072$ mmol) indicated $>99 \%$ conversion to the carboxylic acid $14\left(R_{f}=0.70\right.$ using 8/2 $\mathrm{CH}_{2} \mathrm{Cl}_{2} / \mathrm{MeOH}$ ), which was immediately used in the subsequent Stille coupling.

The Stille reaction was performed under Ar at $23{ }^{\circ} \mathrm{C}$. EtOAc was used to transfer $\mathrm{C}(1)-\mathrm{C}(19)$ vinyl iodide carboxylic acid $14(22 \mathrm{mg}, 41.6 \mu \mathrm{mol})$ and 1.1 equiv of $\mathrm{C}(20)$ C(34) vinyl stannane 21 (33 mg, $0.046 \mathrm{mmol}$ ) into a $15-\mathrm{mL}$ flask. The solution was evaporated to dryness, a magnetic stirrer was added, and all remaining solvent was removed under high vacuum. Dry DMSO and dry THF $(0.6 \mathrm{~mL}$ each) were added under Ar. The solution was degassed 15 times. Degassing was performed on a Schlenk line by 
pulling high vacuum for a few seconds, followed by filling the flask with $\operatorname{Ar} . \operatorname{Pd}\left(\mathrm{PPh}_{3}\right)_{4}$ (0.1 equiv, $4.8 \mathrm{mg}, 0.004 \mathrm{mmol}$ ) was added, and the solution was degassed 10 times. At this point, its color was still weakly yellow. Powdered $\mathrm{CuCl}$ (3 equiv, $13 \mathrm{mg}, 0.126$ mmol) was added, and the mixture was degassed 10 times. Upon degassing, the color of the mixture changed to a dark greenish brown. The mixture was stirred for $2 \mathrm{~h}$, at which point more $\mathrm{Pd}\left(\mathrm{PPh}_{3}\right)_{4}(0.1$ equiv, $4.8 \mathrm{mg}, 0.004 \mathrm{mmol})$ was added followed by degassing 15 times. After another $3 \mathrm{~h}$, the same amount of Pd catalyst was added, which was followed again by degassing. The reaction was allowed to continue for $10 \mathrm{~h}$, thereupon it was taken up in EtOAc and washed with sat. aq. $\mathrm{NH}_{4} \mathrm{Cl}$ and with sat. aq. $\mathrm{NaCl}$. The organic phase was dried over $\mathrm{MgSO}_{4}$ and filtered, and all solvent was evaporated. Since decomposition was observed during previous attempts to purify the intermediate openchain iejimalide B carboxylic acid, the crude reaction product was immediately used in the subsequent macrolactonization.

\section{(B) Shiina Macrolactonization. ${ }^{13}$}

The complete reaction was performed under Ar at $23{ }^{\circ} \mathrm{C}$. To a $50-\mathrm{mL}$ flask were added powdered molecular sieves ( $4 \AA, 500 \mathrm{mg}$ ), which were then flame-dried under high vacuum. After being cooled to $23{ }^{\circ} \mathrm{C}$, the flask was filled with Ar, a magnetic stirrer was added, and the flask was again put under high vacuum to remove any water adsorbed onto the magnetic stirrer, and then filled with Ar. DMAP (6 equiv, $31 \mathrm{mg}, 0.252 \mathrm{mmol}$ ) and MNBA (1.5 equiv, $22 \mathrm{mg}, 0.063 \mathrm{mmol}$ ) were added, and the flask was again held under high vacuum for $2 \mathrm{~h}$, and then filled with Ar. Dry toluene $(14 \mathrm{~mL})$ was added. In another flask, the crude product of reaction A was dissolved in dry toluene $(10 \mathrm{~mL})$ and then added via a syringe pump $(1.5 \mathrm{~mL} / \mathrm{h})$ to the suspension in the first flask. After the addition was completed, the mixture was stirred for another $16 \mathrm{~h}$. It was then diluted with EtOAc and filtered to remove the molecular sieves. The organic phase was washed with sat. aq. $\mathrm{NaHCO}_{3}(2 \mathrm{x})$ and with sat. aq. $\mathrm{NaCl}(2 \mathrm{x})$, dried over $\mathrm{MgSO}_{4}$ and filtered, and all solvent was evaporated.

The formation of the closed iejimalide $\mathrm{B}$ macrocycle could conveniently be confirmed by the presence of the ${ }^{1} \mathrm{H}$ NMR $(S)-\mathrm{C}(17)-O-\mathrm{CH}_{3}$ resonance at around 2.95 ppm in the crude reaction product. This $2.95 \mathrm{ppm}$ resonance is unique to the closed iejimalide B macrocycle: $\delta 2.97\left[(S)-\mathrm{C}(17)-O-\mathrm{CH}_{3}, \mathrm{~s}, 3 \mathrm{H}\right.$, iejimalide $\left.\mathrm{B}(\mathbf{1})\right]$ and $\delta 3.03$ $\left[(S)-\mathrm{C}(17)-\mathrm{O}-\mathrm{CH}_{3}, \mathrm{~s}, 3 \mathrm{H}\right.$, iejimalide $\left.\mathrm{A}\right]$. The open-chain system exhibits this signal at about $3.25 \mathrm{ppm}$.

The residue was then purified by normal phase silica gel chromatography (first column: $2.8 \times 17.5 \mathrm{~cm}$, prepared with $\mathrm{CH}_{2} \mathrm{Cl}_{2}$, sample applied with toluene, gradient $100 \% \mathrm{CH}_{2} \mathrm{Cl}_{2} \rightarrow 7.4 \% \mathrm{MeOH} / \mathrm{CH}_{2} \mathrm{Cl}_{2}$ \& second column: $2.8 \times 14 \mathrm{~cm}$, prepared with $\mathrm{CH}_{2} \mathrm{Cl}_{2}$, sample applied with toluene, gradient $100 \% \mathrm{CH}_{2} \mathrm{Cl}_{2} \rightarrow 3.8 \% \mathrm{MeOH} / \mathrm{CH}_{2} \mathrm{Cl}_{2}$ ). After both chromatographic purifications, only fractions containing the desired ${ }^{1} \mathrm{H}$ NMR resonance at $\sim 2.95 \mathrm{ppm}$ were combined. The resulting crude product was purified by

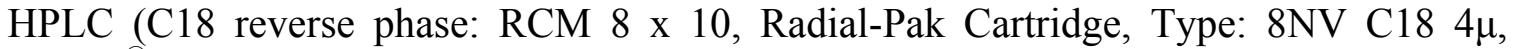
Waters ${ }^{\circledR}$ HPLC system, $80 / 20 \mathrm{MeCN} / \mathrm{H}_{2} \mathrm{O}, 1 \mathrm{~mL} / \mathrm{min}, t_{\mathrm{R}}=53 \mathrm{~min}$ ) to provide pure desired $O$-TBS-protected iejimalide B (22) (6 mg, $7.43 \mu \mathrm{mol}, 18-25 \%$ yield over 2 steps). 
${ }^{1} \mathrm{H}$ NMR $\left(500 \mathrm{MHz}, \mathrm{CDCl}_{3}, 23{ }^{\circ} \mathrm{C}\right): \delta=8.28\left(\mathrm{~s}, 1 \mathrm{H}, \mathrm{H}_{34}\right), 6.62(\mathrm{dd}, 1 \mathrm{H}, J=1.4,10.4$ $\left.\mathrm{Hz}, \mathrm{H}_{3}\right), 6.57\left(\mathrm{~m}, 2 \mathrm{H}, \mathrm{NH}_{30}, \mathrm{NH}_{33}\right), 6.50\left(\mathrm{~d}, 1 \mathrm{H}, J=15.8 \mathrm{~Hz}, \mathrm{H}_{12}\right), 6.28(\mathrm{~d}, 1 \mathrm{H}, J=11.2$ $\left.\mathrm{Hz}, \mathrm{H}_{26}\right), 6.14$ (d, $\left.1 \mathrm{H}, J=11.2 \mathrm{~Hz}, \mathrm{H}_{27}\right), 6.02\left(\mathrm{~m}, 2 \mathrm{H}, \mathrm{H}_{19}, \mathrm{H}_{20}\right), 5.86(\mathrm{~d}, 1 \mathrm{H}, J=15.4$ $\left.\mathrm{Hz}, \mathrm{H}_{6}\right), 5.54-5.35\left(\mathrm{~m}, 4 \mathrm{H}, \mathrm{H}_{5}, \mathrm{H}_{11}, \mathrm{H}_{18}, \mathrm{H}_{21}\right), 5.19$ (dd, $\left.1 \mathrm{H}, J=5.8,11.2 \mathrm{~Hz}, \mathrm{H}_{14}\right), 5.15$ (d, $\left.1 \mathrm{H}, J=10.4 \mathrm{~Hz}, \mathrm{H}_{23}\right), 5.09$ (d, $\left.1 \mathrm{H}, J=9.6 \mathrm{~Hz}, \mathrm{H}_{8}\right), 4.46\left(\mathrm{~m}, 1 \mathrm{H}, \mathrm{H}_{32}\right), 4.12(\mathrm{~m}, 2 \mathrm{H}$, $\mathrm{H}_{9}, \mathrm{H}_{35}$ ), 3.91 (m, $2 \mathrm{H}, \mathrm{H}_{29}$ ), 3.59 (app. t, $\left.1 \mathrm{H}, \mathrm{H}_{35}\right), 3.28$ (m, $1 \mathrm{H}, \mathrm{H}_{17}$ ), 3.26 (s, $3 \mathrm{H}, \mathrm{H}_{41}$ ), $3.14\left(\mathrm{~m}, 1 \mathrm{H}, \mathrm{H}_{4}\right), 2.95\left(\mathrm{~s}, 3 \mathrm{H}, \mathrm{H}_{39}\right), 2.67\left(\mathrm{~m}, 1 \mathrm{H}, \mathrm{H}_{10}\right), 2.55\left(\mathrm{~m}, 2 \mathrm{H}, \mathrm{H}_{15}, \mathrm{H}_{22}\right), 2.32(\mathrm{~m}$, $\left.1 \mathrm{H}, \mathrm{H}_{10}\right), 1.90\left(\mathrm{~m}, 1 \mathrm{H}, \mathrm{H}_{15}\right), 1.81-1.75$ (5 overlapping s, $15 \mathrm{H}, \mathrm{H}_{36}, \mathrm{H}_{37}, \mathrm{H}_{40}, \mathrm{H}_{42}, \mathrm{H}_{44}$ ), $1.63\left(\mathrm{~m}, 1 \mathrm{H}, \mathrm{H}_{16}\right), 1.33\left(\mathrm{~m}, 1 \mathrm{H}, \mathrm{H}_{16}\right), 1.05\left(\mathrm{~d}, 3 \mathrm{H}, J=6.8 \mathrm{~Hz}, \mathrm{H}_{43}\right), 0.92(\mathrm{~d}, 3 \mathrm{H}, J=7.4$ $\left.\mathrm{Hz}, \mathrm{H}_{38}\right), 0.88$ (s, $\left.9 \mathrm{H}, \mathrm{Si}-\mathrm{C}\left(\mathrm{CH}_{3}\right)_{3}\right), 0.12$ (s, $\left.3 \mathrm{H}, \mathrm{Si}_{-} \mathrm{CH}_{3}\right), 0.09$ ppm (s, $\left.3 \mathrm{H}, \mathrm{Si}-\mathrm{CH}_{3}\right)$. HRMS (FAB+) $\mathrm{m} / \mathrm{z}\left([\mathrm{M}+\mathrm{H}]^{+}\right)$: Calcd for $\mathrm{C}_{47} \mathrm{H}_{75} \mathrm{~N}_{2} \mathrm{O}_{7} \mathrm{Si}_{1}:$ : 807.5344, Found: 807.5320.

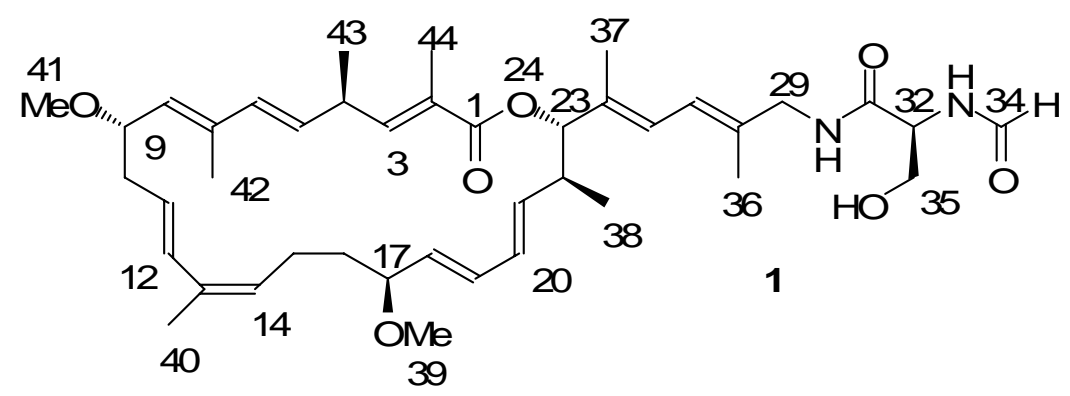

Iejimalide B (1).

Using EtOAc $(1 \times 300 \mu \mathrm{L})$ and DMF $(1 \times 300 \mu \mathrm{L} \& 1 \times 150 \mu \mathrm{L})$, $O$-TBSprotected iejimalide B (22) $(3 \mathrm{mg}, 3.7 \mu \mathrm{mol})$ was transferred from a 15 -mL flask into a plastic vial. TAS-F (10 equiv, $0.5 \mathrm{M}$ in DMF, $74 \mu \mathrm{L}, 0.037 \mathrm{mmol}$ ) was added, the solution was shaken, and the reaction was allowed to proceed for $2 \mathrm{~h}$ at $23{ }^{\circ} \mathrm{C}$. The solution was diluted with $\mathrm{pH} 7$ buffer, and extracted with EtOAc $(3 \mathrm{x})$. The combined organic phase was dried over $\mathrm{MgSO}_{4}$ and filtered, and all solvent was evaporated. The resulting crude product was purified by normal phase silica gel chromatography $(2.8 \mathrm{x}$ $17.5 \mathrm{~cm}$, prepared with $\mathrm{CH}_{2} \mathrm{Cl}_{2}$, sample applied with toluene, gradient $100 \% \mathrm{CH}_{2} \mathrm{Cl}_{2} \rightarrow$ $10 \% \mathrm{MeOH} / \mathrm{CH}_{2} \mathrm{Cl}_{2}$ ). Only fractions containing the desired ${ }^{1} \mathrm{H}$ NMR resonance at $\sim 2.95$ ppm were combined. HPLC (C18 reverse phase: RCM 8 x 10, Radial-Pak Cartridge, Type: $8 \mathrm{NV} \mathrm{C18} 4 \mu$, Waters ${ }^{\circledR} \mathrm{HPLC}$ system, $1 \mathrm{~mL} / \mathrm{min}, t_{\mathrm{R}}=15 \mathrm{~min}$ for $70 / 30 \mathrm{MeCN} / \mathrm{H}_{2} \mathrm{O}$ and $t_{\mathrm{R}}=33 \mathrm{~min}$ for $60 / 40 \mathrm{MeCN} / \mathrm{H}_{2} \mathrm{O}$ ) purification provided pure, final, desired iejimalide B (1) (2 mg, $3 \mu \mathrm{mol}, 80 \%$ yield). The synthetic iejimalide B is identical to the natural iejimalide $\mathrm{B}$ isolated in our laboratory.

${ }^{1} \mathrm{H}$ NMR $\left(500 \mathrm{MHz}, \mathrm{CDCl}_{3}, 23{ }^{\circ} \mathrm{C}\right): \delta=8.30\left(\mathrm{~s}, 1 \mathrm{H}, \mathrm{H}_{34}\right), 6.76(\mathrm{~d}, 1 \mathrm{H}, J=6.6 \mathrm{~Hz}$, $\left.\mathrm{NH}_{33}\right), 6.71\left(\mathrm{~m}, 1 \mathrm{H}, \mathrm{NH}_{30}\right), 6.63\left(\mathrm{dd}, 1 \mathrm{H}, J=1.5,10.3 \mathrm{~Hz}, \mathrm{H}_{3}\right), 6.48(\mathrm{~d}, 1 \mathrm{H}, J=15.6$ $\left.\mathrm{Hz}, \mathrm{H}_{12}\right), 6.28\left(\mathrm{~d}, 1 \mathrm{H}, J=11.4 \mathrm{~Hz}, \mathrm{H}_{26}\right), 6.13\left(\mathrm{~d}, 1 \mathrm{H}, J=11.2 \mathrm{~Hz}, \mathrm{H}_{27}\right), 6.03(\mathrm{~m}, 2 \mathrm{H}$, $\mathrm{H}_{19}, \mathrm{H}_{20}$ ), 5.86 (d, $\left.1 \mathrm{H}, J=15.4 \mathrm{~Hz}, \mathrm{H}_{6}\right), 5.54-5.37$ (m, $\left.4 \mathrm{H}, \mathrm{H}_{5}, \mathrm{H}_{11}, \mathrm{H}_{18}, \mathrm{H}_{21}\right), 5.19$ (dd, $\left.1 \mathrm{H}, J=6.2,11.0 \mathrm{~Hz}, \mathrm{H}_{14}\right), 5.15\left(\mathrm{~d}, 1 \mathrm{H}, J=10.0 \mathrm{~Hz}, \mathrm{H}_{23}\right), 5.08\left(\mathrm{~d}, 1 \mathrm{H}, J=9.0 \mathrm{~Hz}, \mathrm{H}_{8}\right.$ ), $4.50\left(\mathrm{~m}, 1 \mathrm{H}, \mathrm{H}_{32}\right), 4.23\left(\mathrm{dd}, 1 \mathrm{H}, J=2.5,11.5 \mathrm{~Hz}, \mathrm{H}_{35}\right), 4.13\left(\mathrm{~m}, 1 \mathrm{H}, \mathrm{H}_{9}\right), 3.90(\mathrm{~m}, 2 \mathrm{H}$, $\mathrm{H}_{29}$ ), $3.65\left(\mathrm{~m}, 1 \mathrm{H}, \mathrm{H}_{35}\right), 3.28\left(\mathrm{~m}, 1 \mathrm{H}, \mathrm{H}_{17}\right), 3.27\left(\mathrm{~s}, 3 \mathrm{H}, \mathrm{H}_{41}\right), 3.14\left(\mathrm{~m}, 1 \mathrm{H}, \mathrm{H}_{4}\right), 2.97$ (s, $\left.3 \mathrm{H}, \mathrm{H}_{39}\right), 2.68\left(\mathrm{~m}, 1 \mathrm{H}, \mathrm{H}_{10}\right), 2.55\left(\mathrm{~m}, 2 \mathrm{H}, \mathrm{H}_{15}, \mathrm{H}_{22}\right), 2.32\left(\mathrm{~m}, 1 \mathrm{H}, \mathrm{H}_{10}\right), 1.90(\mathrm{~m}, 1 \mathrm{H}$, $\mathrm{H}_{15}$ ), 1.80 - 1.75 (5 overlapping s, $\left.15 \mathrm{H}, \mathrm{H}_{36}, \mathrm{H}_{37}, \mathrm{H}_{40}, \mathrm{H}_{42}, \mathrm{H}_{44}\right), 1.62\left(\mathrm{~m}, 1 \mathrm{H}, \mathrm{H}_{16}\right), 1.33$ $\left(\mathrm{m}, 1 \mathrm{H}, \mathrm{H}_{16}\right), 1.05\left(\mathrm{~d}, 3 \mathrm{H}, J=6.8 \mathrm{~Hz}, \mathrm{H}_{43}\right), 0.94 \mathrm{ppm}\left(\mathrm{d}, 3 \mathrm{H}, J=6.6 \mathrm{~Hz}, \mathrm{H}_{38}\right)$. HRMS 
$(\mathrm{FAB}+) \mathrm{m} / \mathrm{z}\left([\mathrm{M}+\mathrm{H}]^{+}\right)$: Calcd for $\mathrm{C}_{41} \mathrm{H}_{61} \mathrm{~N}_{2} \mathrm{O}_{7}$ : 693.4479, Found: 693.4453 and $(\mathrm{FAB}+)$ $\mathrm{m} / \mathrm{z}\left([\mathrm{M}+\mathrm{Na}]^{+}\right)$: Calcd for $\mathrm{C}_{41} \mathrm{H}_{60} \mathrm{~N}_{2} \mathrm{Na}_{1} \mathrm{O}_{7}$ : 715.4298, Found: 715.4283.

\section{Crystal Violet Cell Number Assay.}

LNCaP cells were grown in RPMI 1640 medium supplemented with 10\% FBS and $1 \%$ penicillin/streptomycin for $24 \mathrm{~h}$ prior to treatment and fixed with $2 \%$ glutaraldehyde in PBS after 72 or $96 \mathrm{~h}$. For each substance, three parallel experiments were performed. Fixed cells were stained with $0.1 \%$ crystal violet and washed in deionized water, and the bound dye was solubilized in $0.2 \%$ Triton X-100 and measured for optical density at $590 \mathrm{~nm}$.

\section{References.}

(1) Lafontaine, J. A., Ph.D. Dissertation, University of California, Berkeley, CA, 1998.

(2) Mendlik, M. T.; Cottard, M.; Rein, T.; Helquist, P. Tetrahedron Lett. 1997, 38, 6375.

(3) (a) Merlic, C. A.; Aldrich, C. C.; Albaneze-Walker, J.; Saghatelian, A.; Mammen, J. J. Org. Chem. 2001, 66, 1297.

(b) Nyström, J.-E.; McCanna, T. D.; Helquist, P.; Amouroux, R. Synthesis 1988, 56.

(4) (a) Kim, D.-K.; Kim, G.; Gam, J.; Cho, Y.-B.; Kim, H.-T.; Tai, J.-H.; Kim, K. H.; Hong, W.-S.; Park, J.-G. J. Med. Chem. 1994, 37, 1471.

(b) Nemoto, H.; Ishibashi, H.; Nagamochi, M.; Fukumoto, K. J. Org. Chem. 1992, 57, 1707.

(5) Mori, K.; Koseki, K. Tetrahedron 1988, 44, 6013.

(6) (a) Oestreich, M.; Fröhlich, R.; Hoppe, D. J. Org. Chem. 1999, 64, 8616.

(b) Van de Weghe, P.; Bourg, S.; Eustache, J. Tetrahedron 2003, 59, 7365.

(7) Wipf, P.; Graham, T. H. J. Am. Chem. Soc. 2004, 126, 15346.

(8) Kalish, V. J.; Shone, R. L.; Kramer, S. W.; Collins, P. W. Synth. Commun. 1990, 20, 1641.

(9) Alvarez, R.; Domínguez, M.; Pazos, Y.; Sussman, F.; de Lera, A. R. Chem. Eur. J. 2003, 9, 5821 .

(10) (a) Danheiser, R. L.; Carini, D. J.; Fink, D. M.; Basak, A. Tetrahedron 1983, 39, 935.

(b) Fleming, I.; Takaki, K.; Thomas, A. P. J. Chem. Soc., Perkin Trans. 1 1987, 2269.

(c) Pearson, A. J.; Kim, J. B. Org. Lett. 2002, 4, 2837.

(11) (a) Marshall, J. A.; Chobanian, H. R.; Yanik, M. M. Org. Lett. 2001, 3, 3369.

(b) Marshall, J. A.; Grant, C. M. J. Org. Chem. 1999, 64, 696.

(12) (a) Betzer, J.-F.; Lallemand, J.-Y.; Pancrazi, A. Synthesis 1998, 522.

(b) Munakata, R.; Katakai, H.; Ueki, T.; Kurosaka, J.; Takao, K.-I.; Tadano, K.-I. J. Am. Chem. Soc. 2004, 126, 11254.

(13) (a) Shiina, I.; Kubota, M.; Oshiumi, H.; Hashizume, M. J. Org. Chem. 2004, 69, 1822.

(b) Wu, Y.; Yang, Y.-Q. J. Org. Chem. 2006, 71, 4296. 


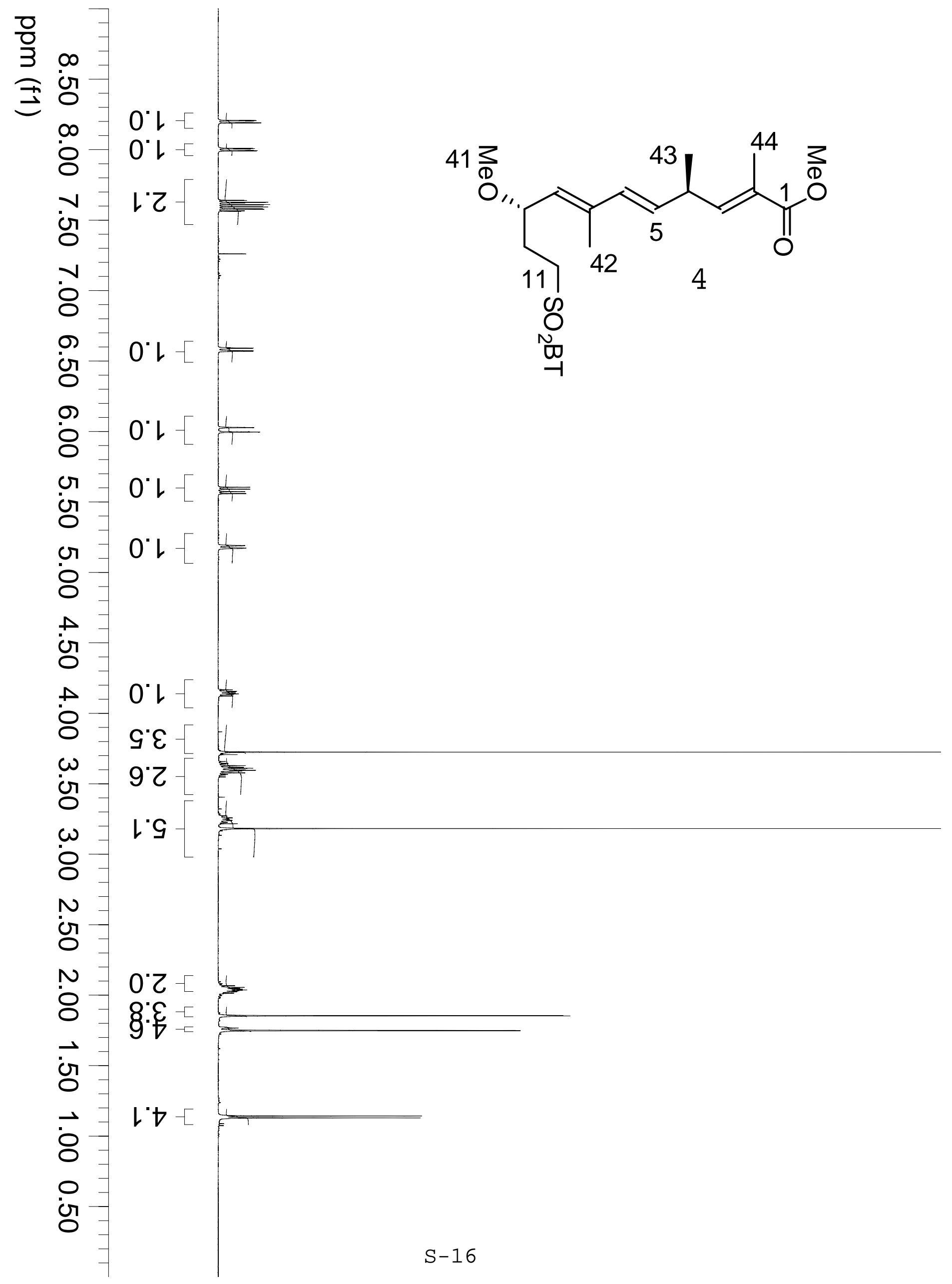




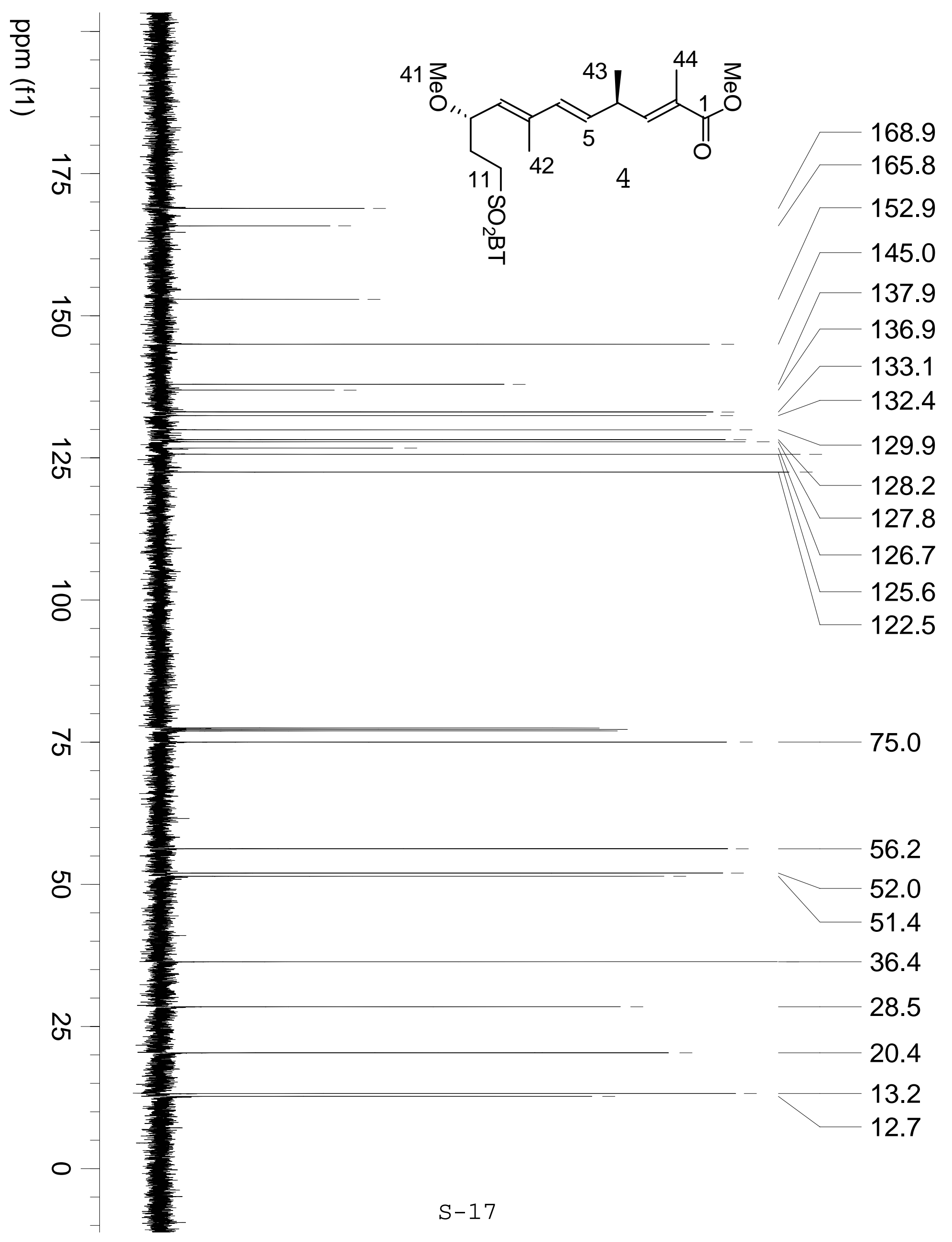




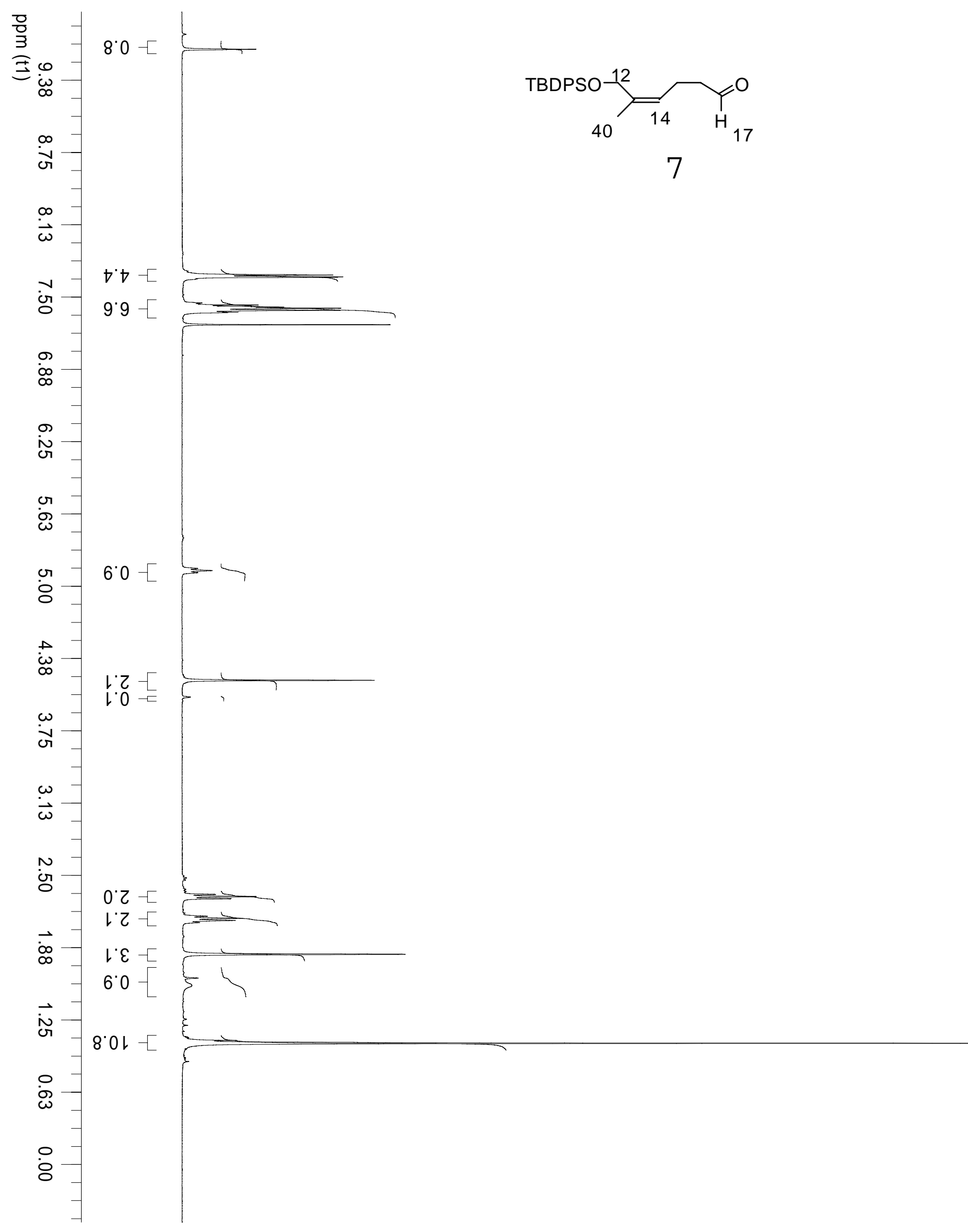




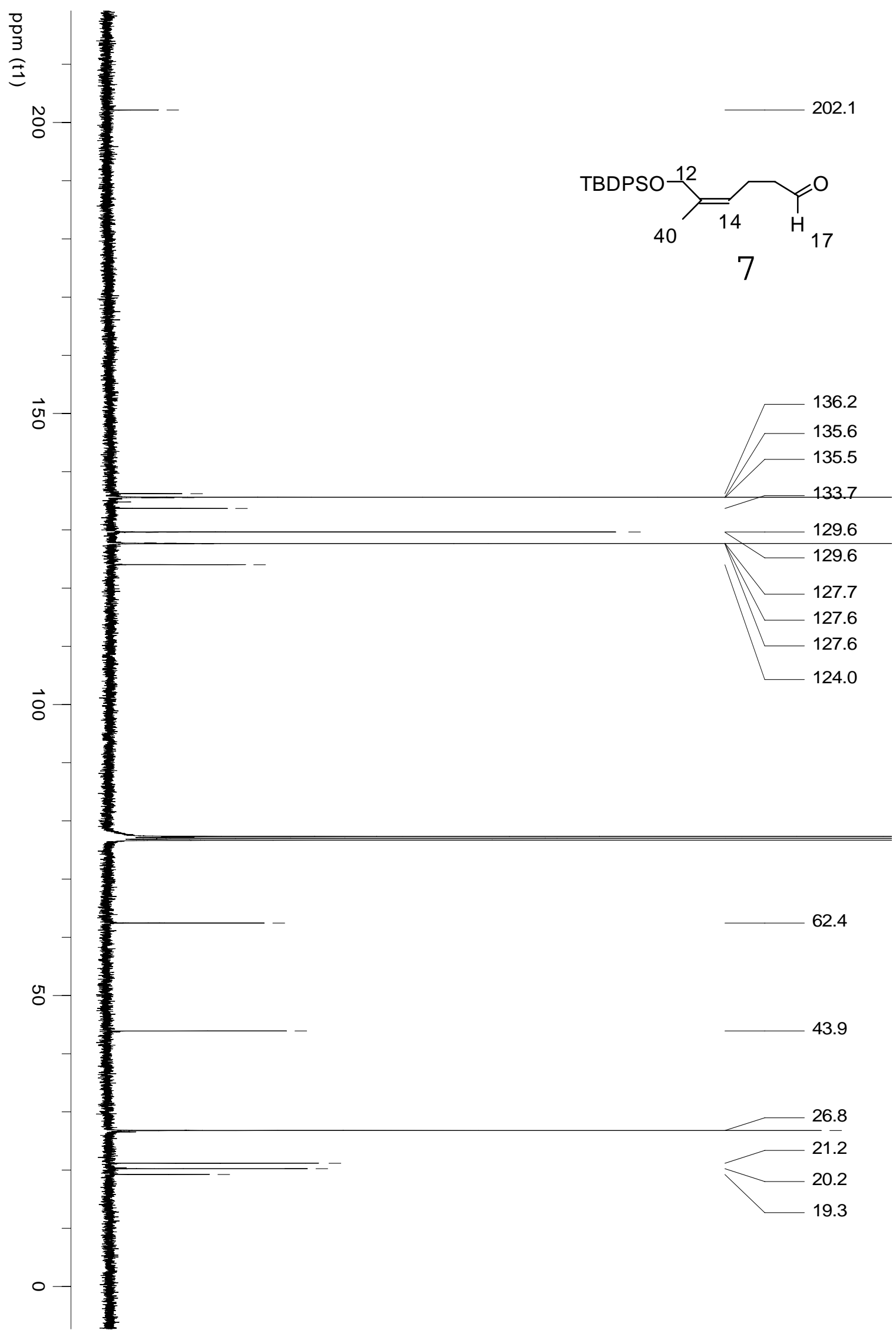




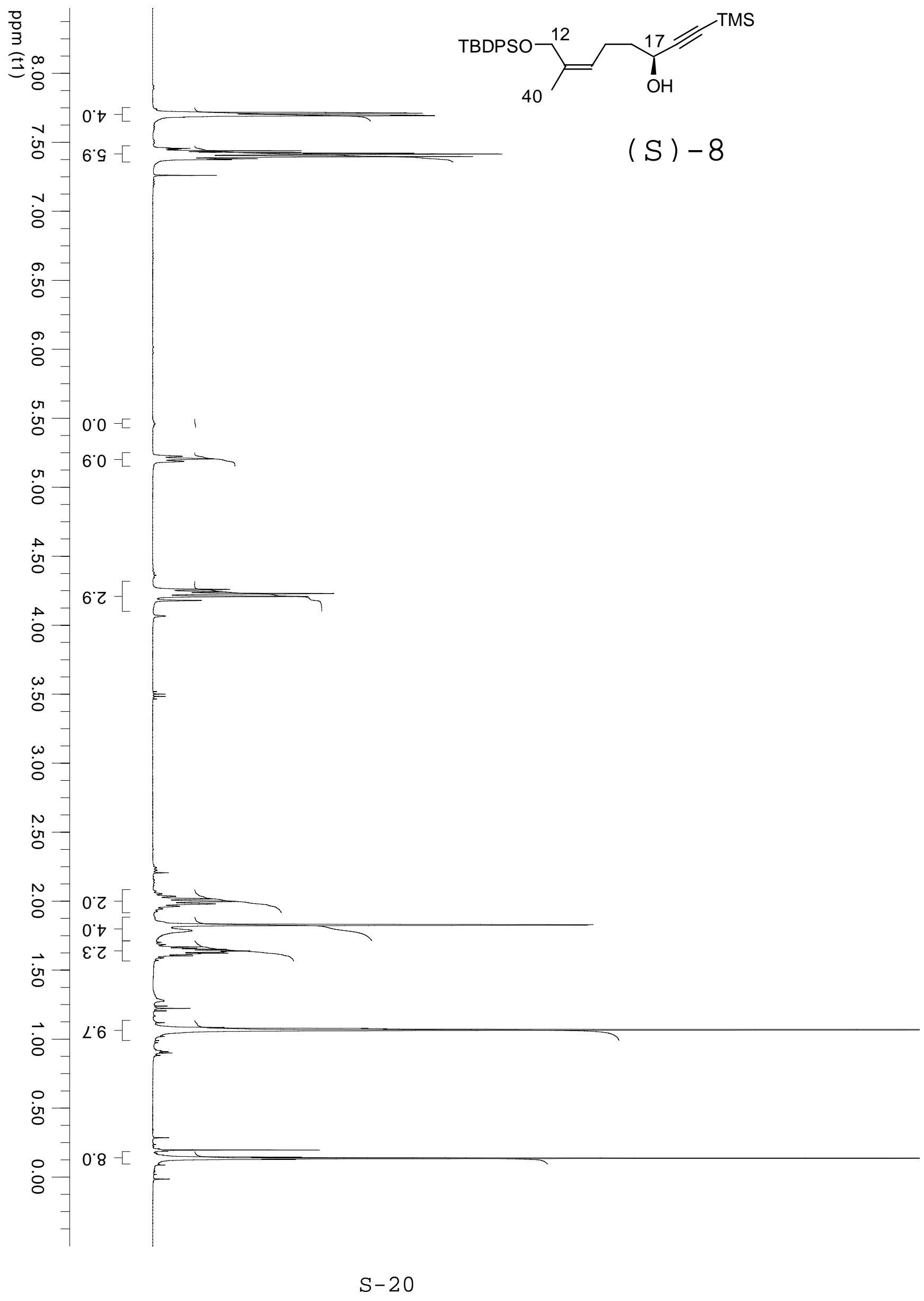




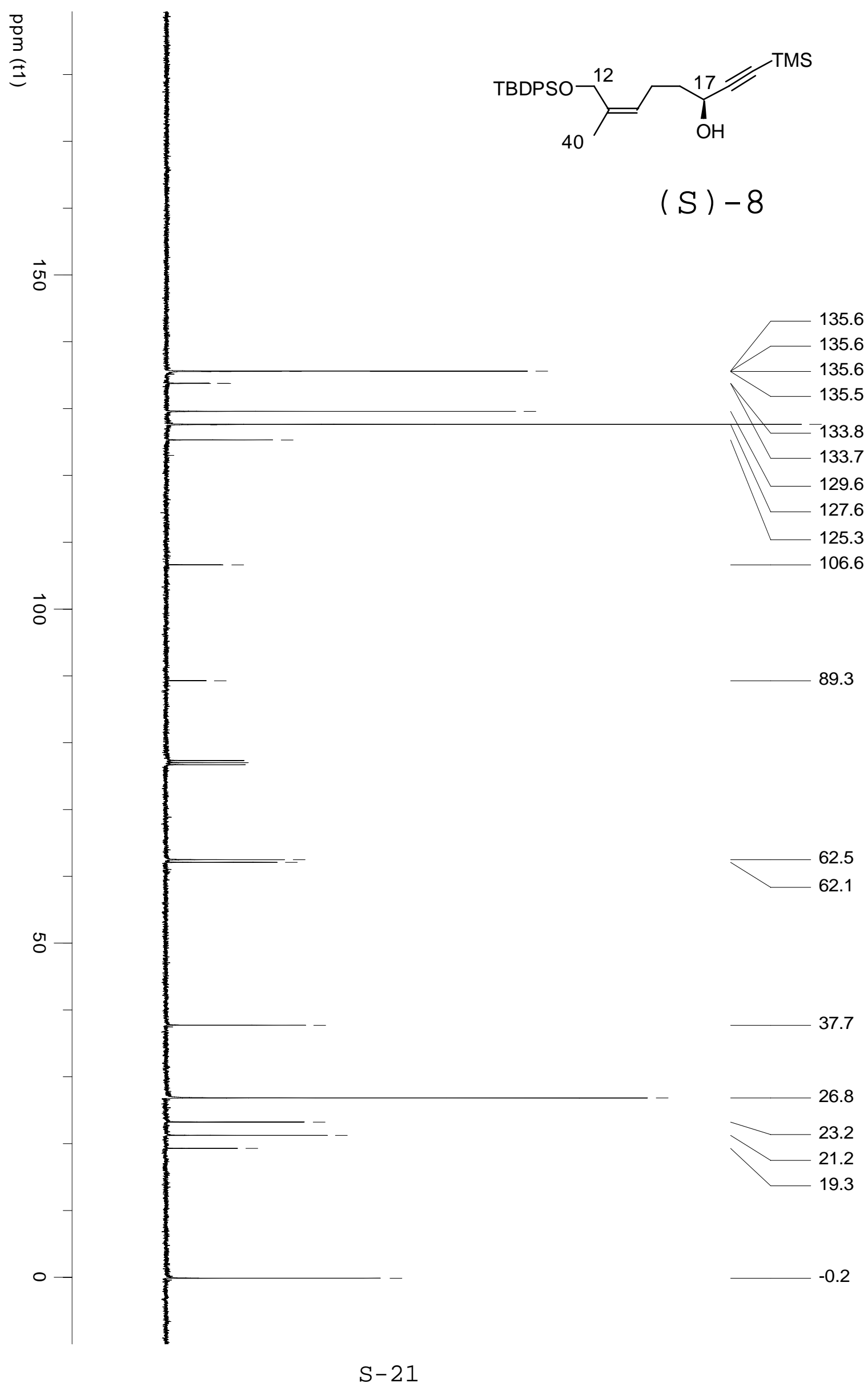




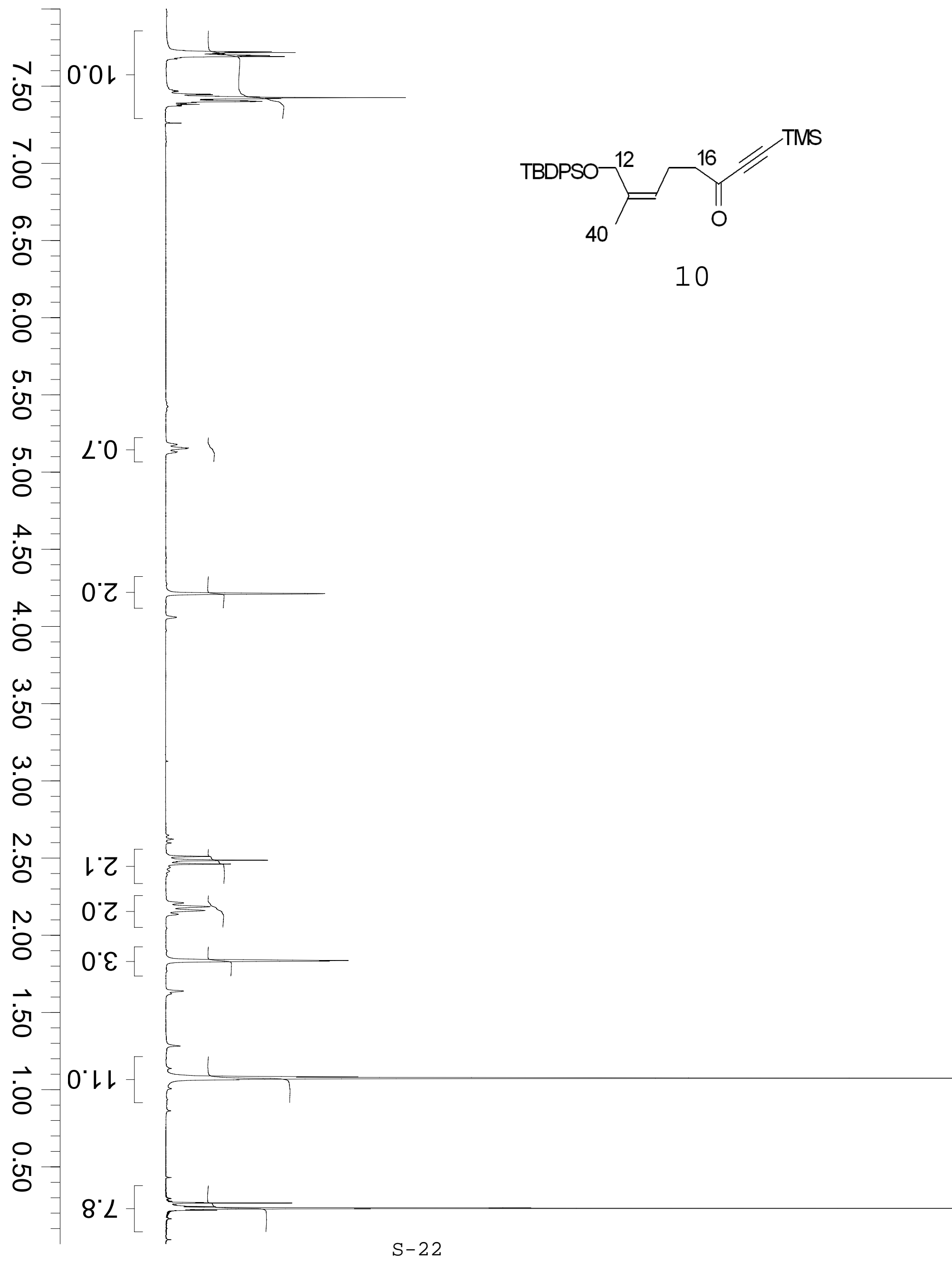




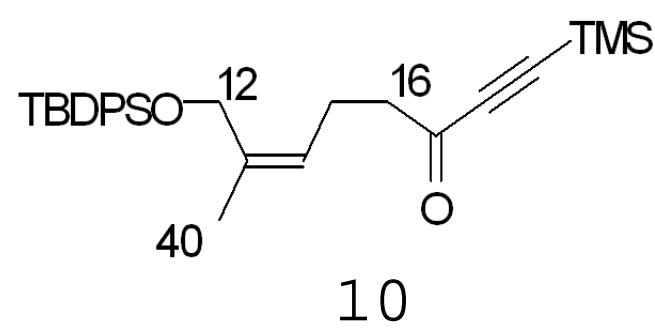

$\ddot{\bullet}$

요요

102.1

97.9

77.7

77.2

76.8

62.6

용

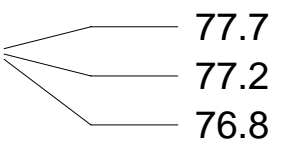

45.6

45.4

27.0

22.3

22.1

21.4

19.5

0

$-0.6$

$S-23$ 


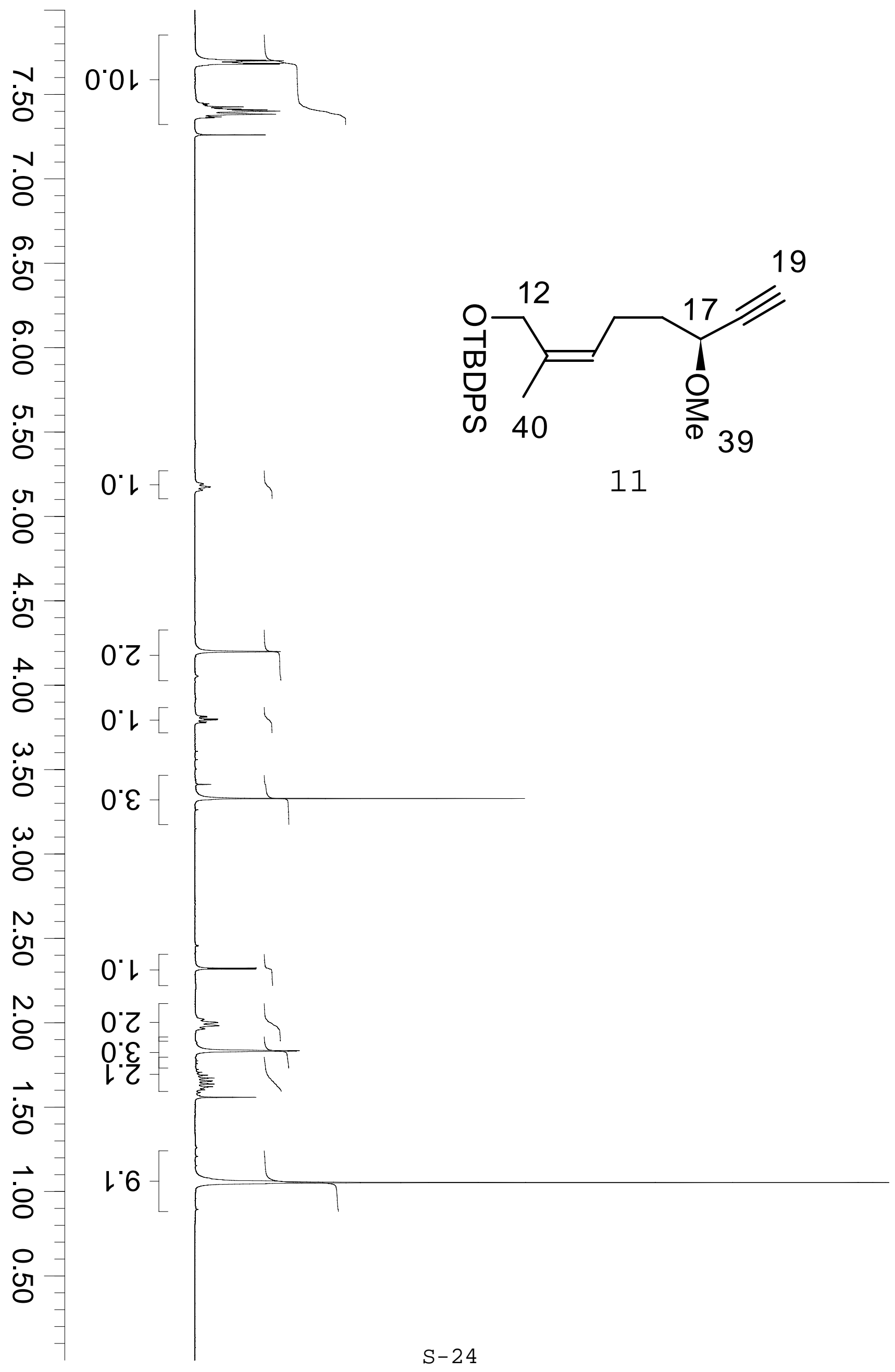




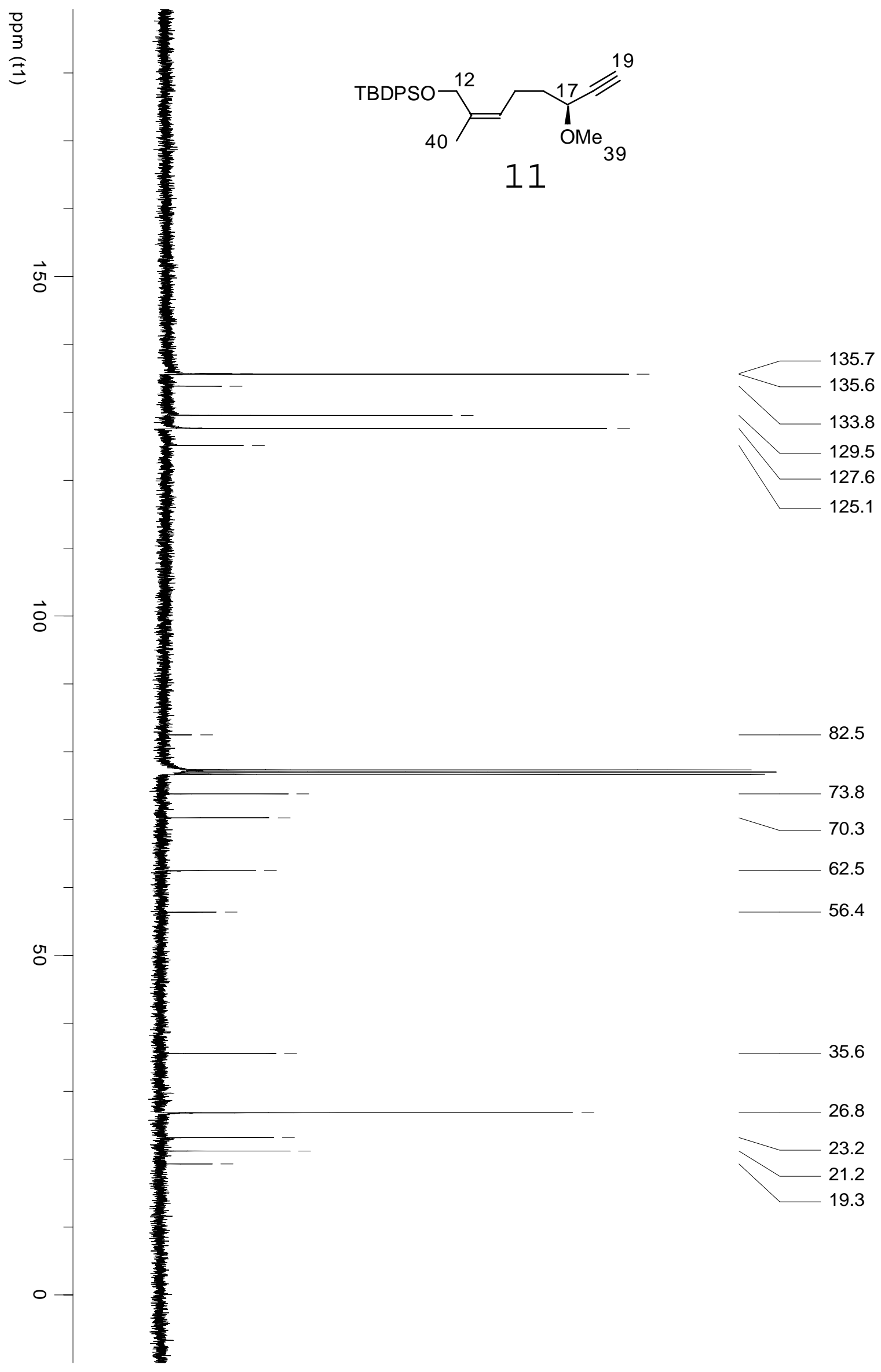

$S-25$ 


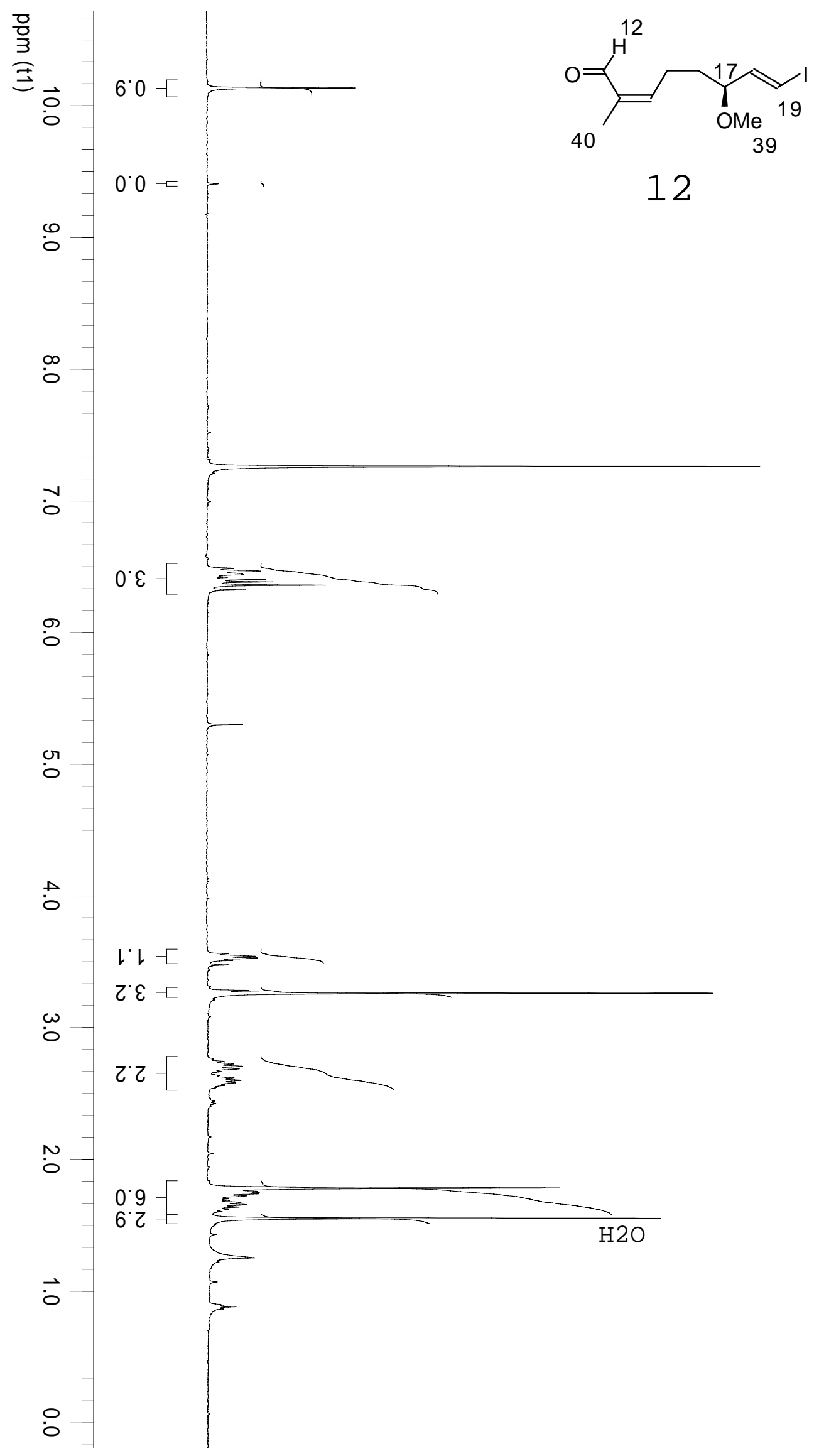




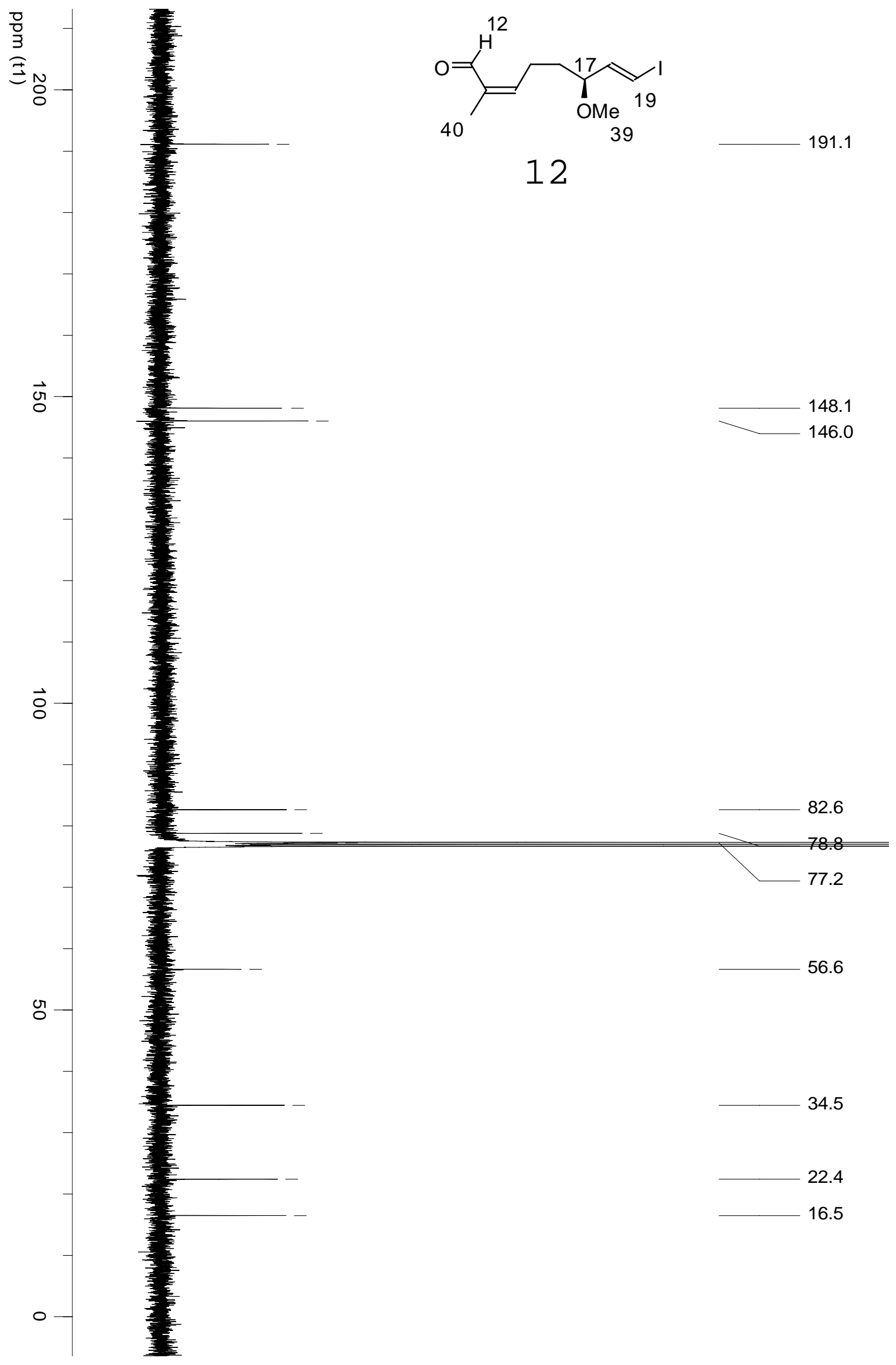




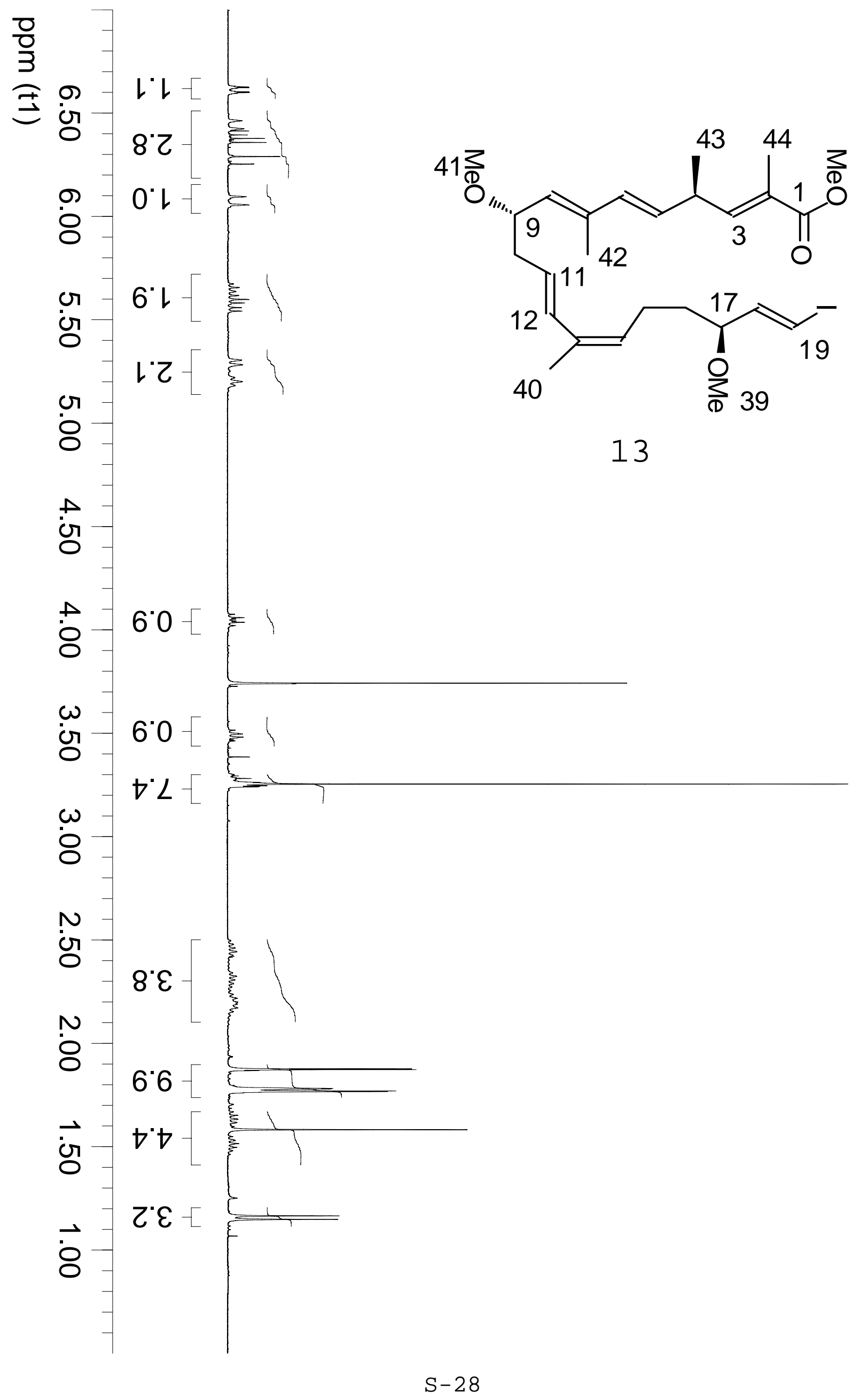




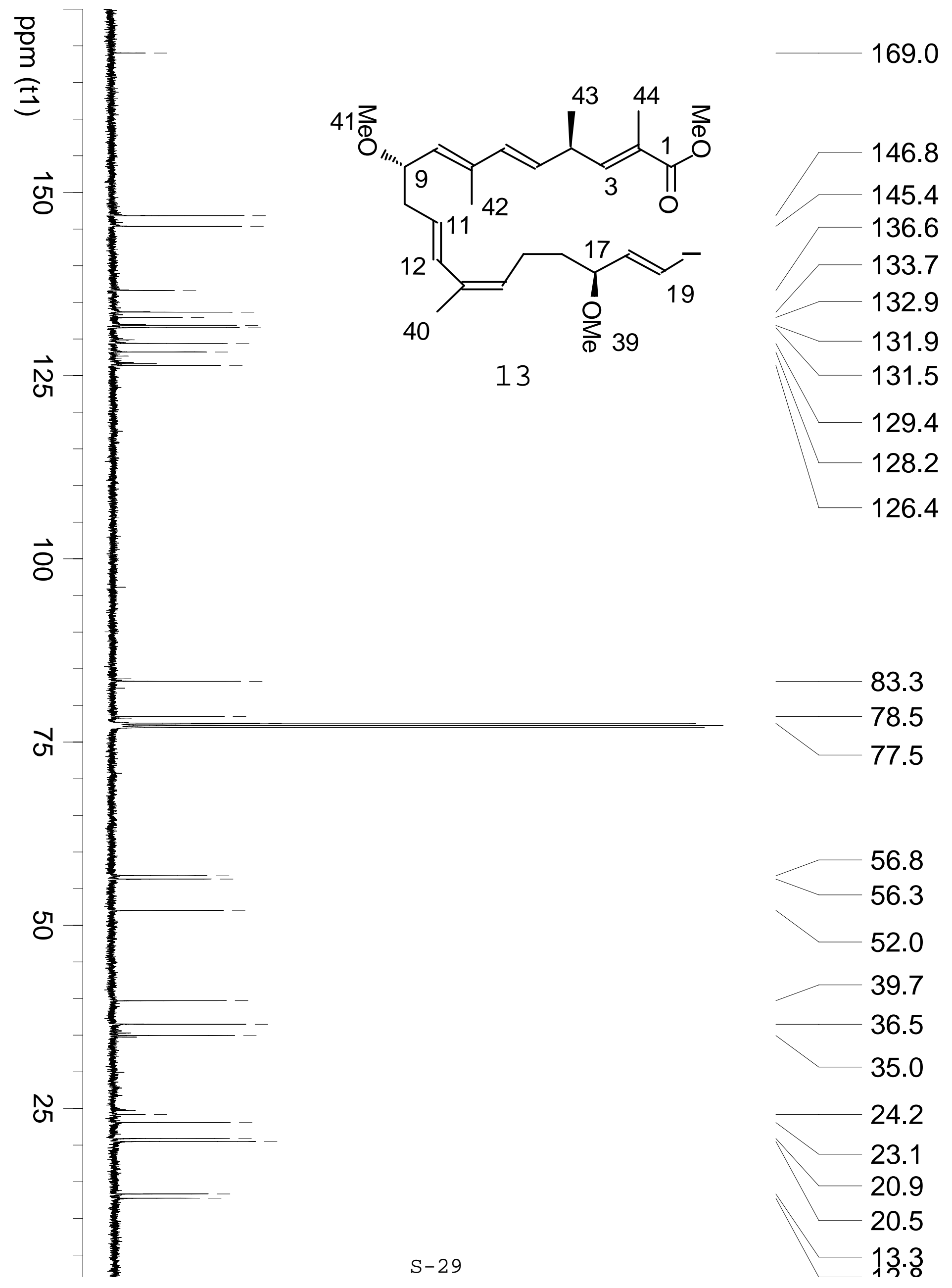




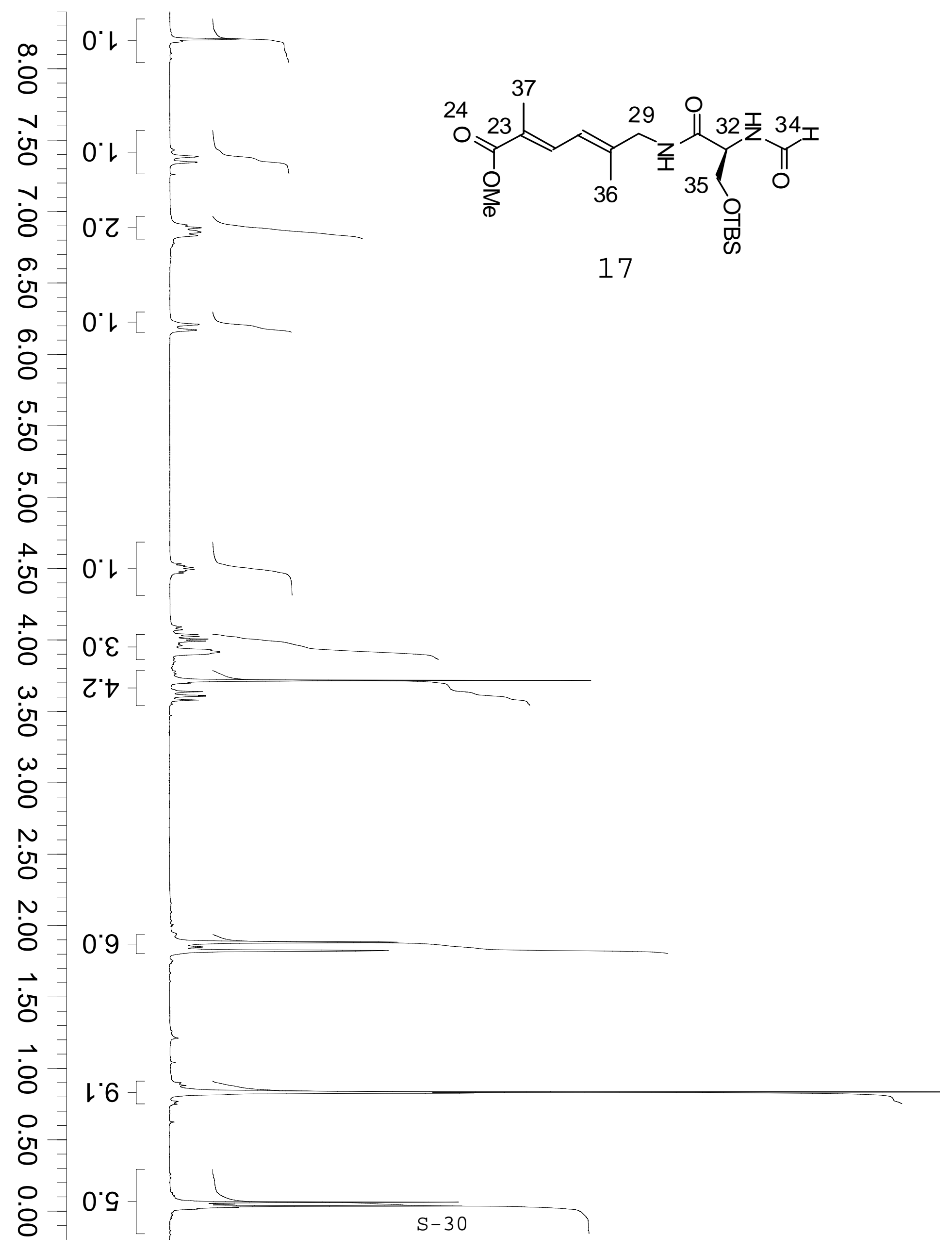




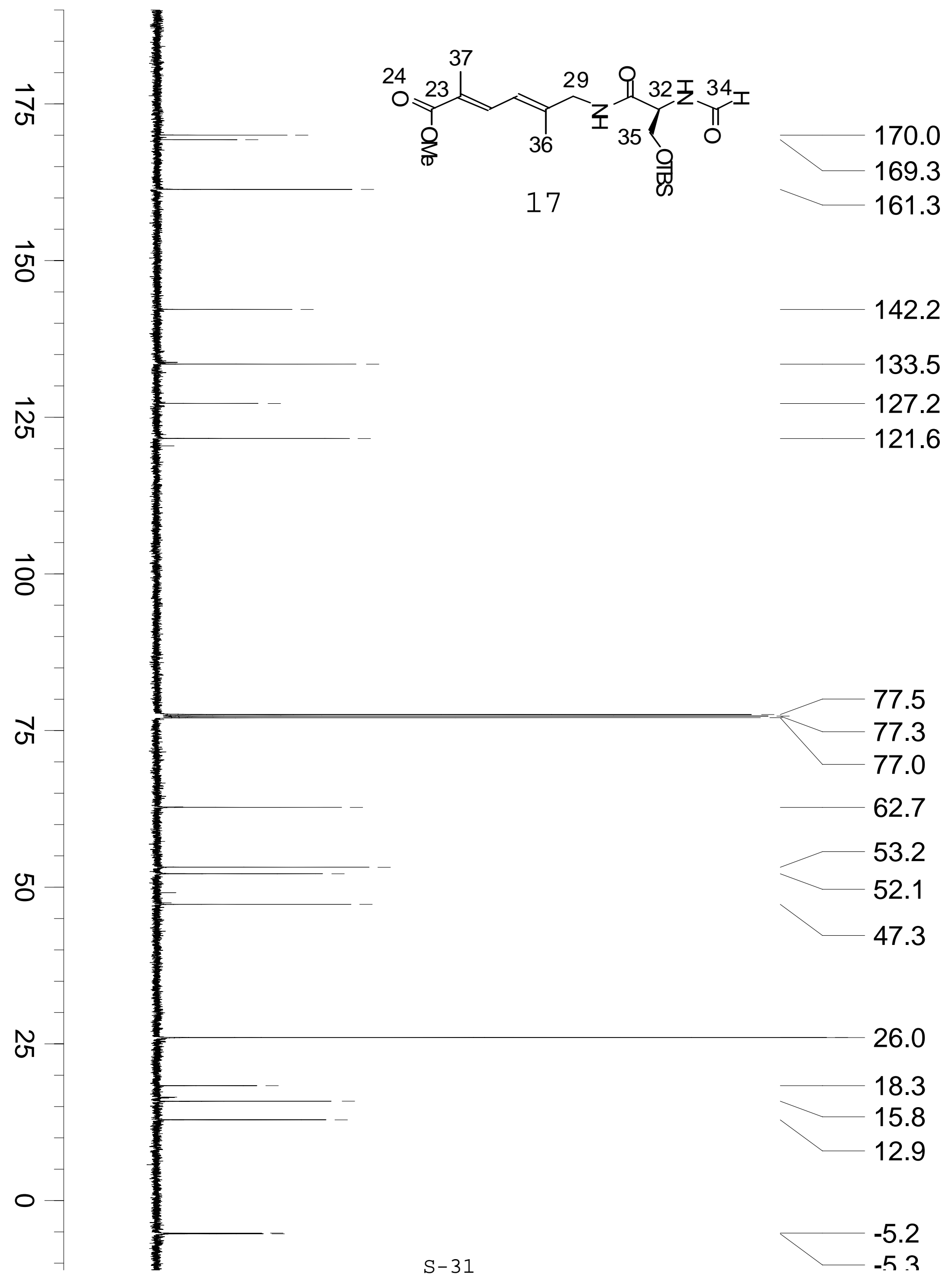




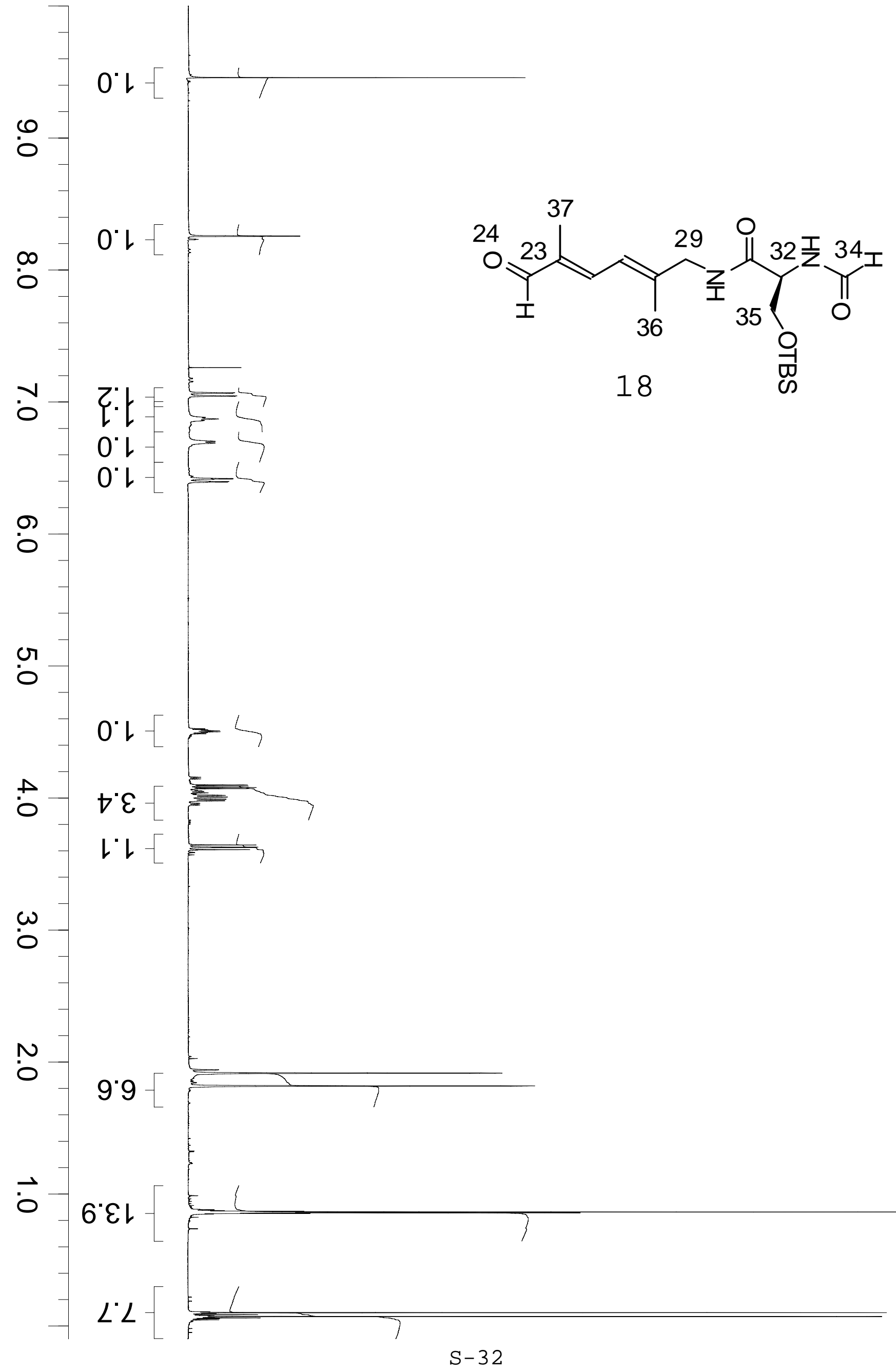




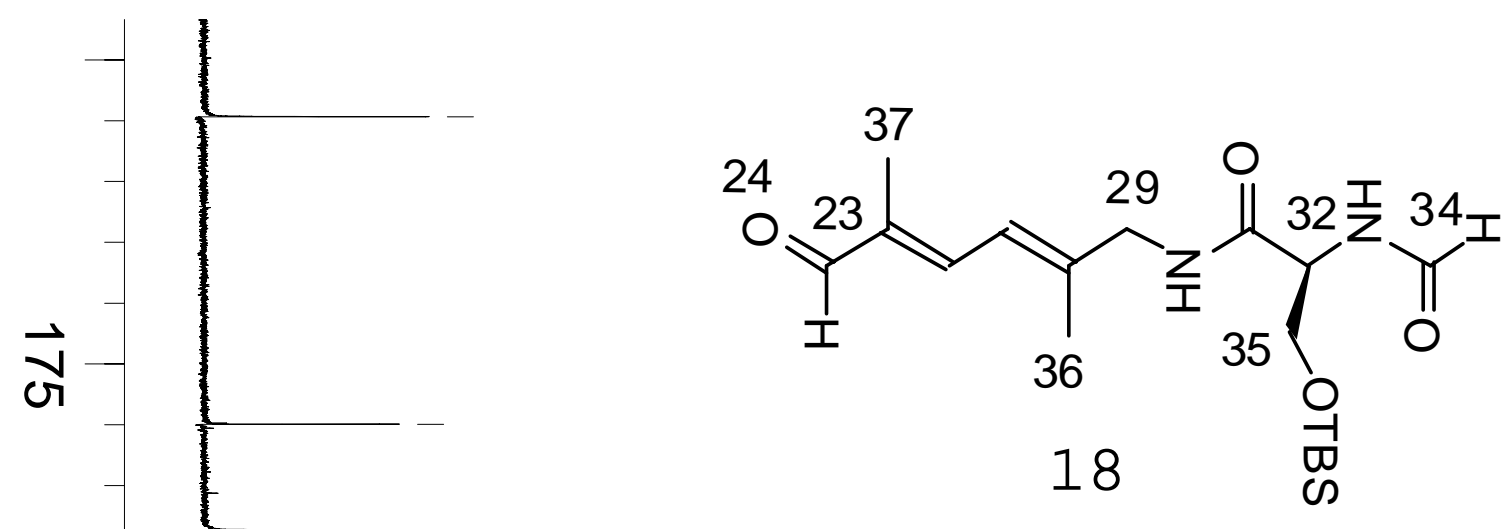

195.3

170.0

161.3

145.1

143.6

137.8

121.1

77.5

77.2

77.0

62.7

53.2

47.1

25.9

N

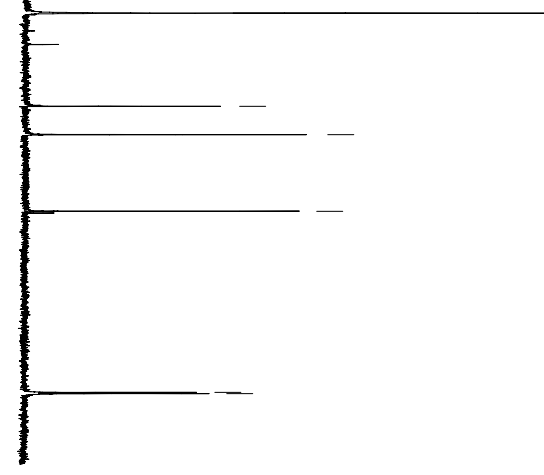

$S-33$

18.2

15.9

9.6

$-5.3$

$-54$ 


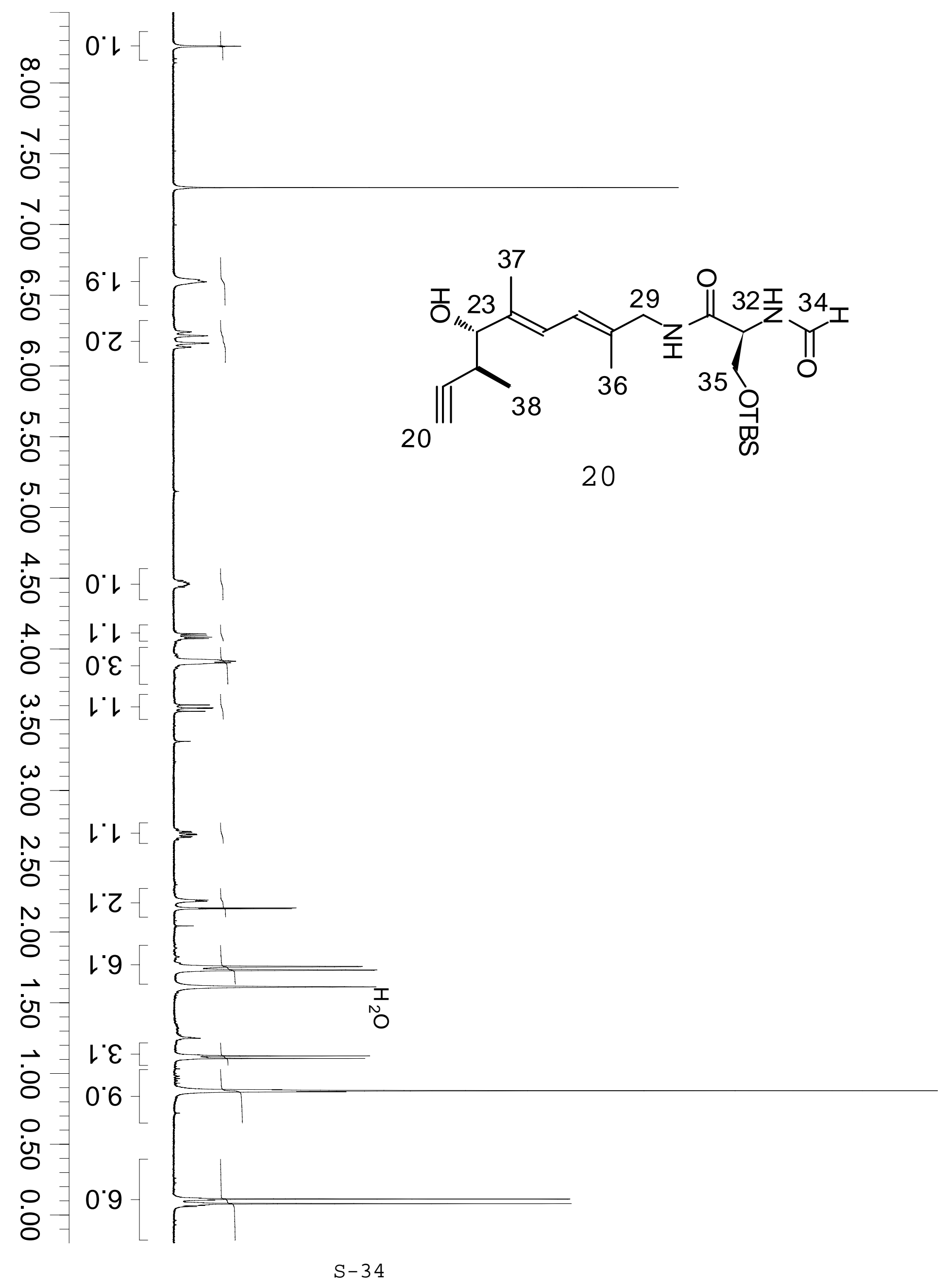




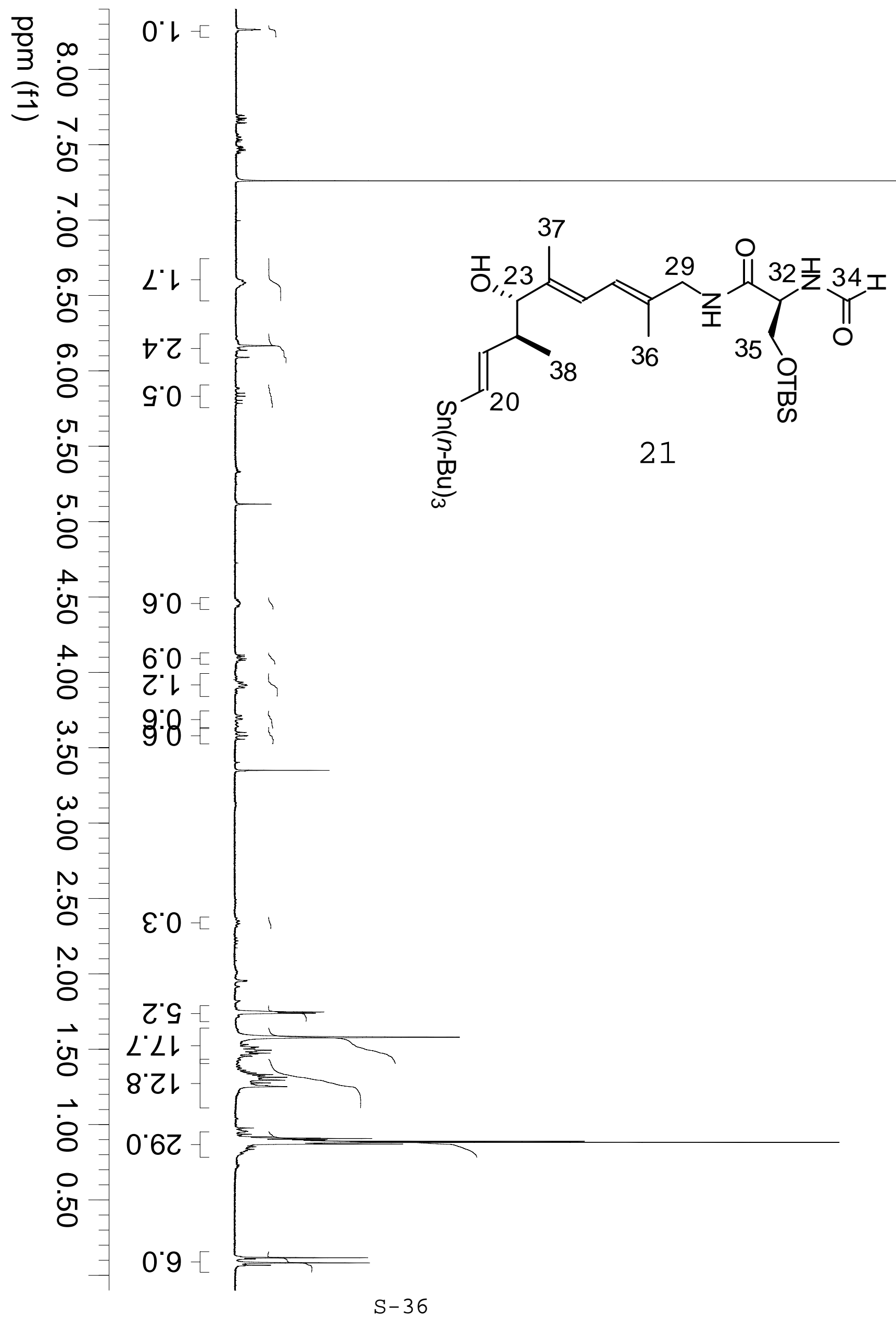




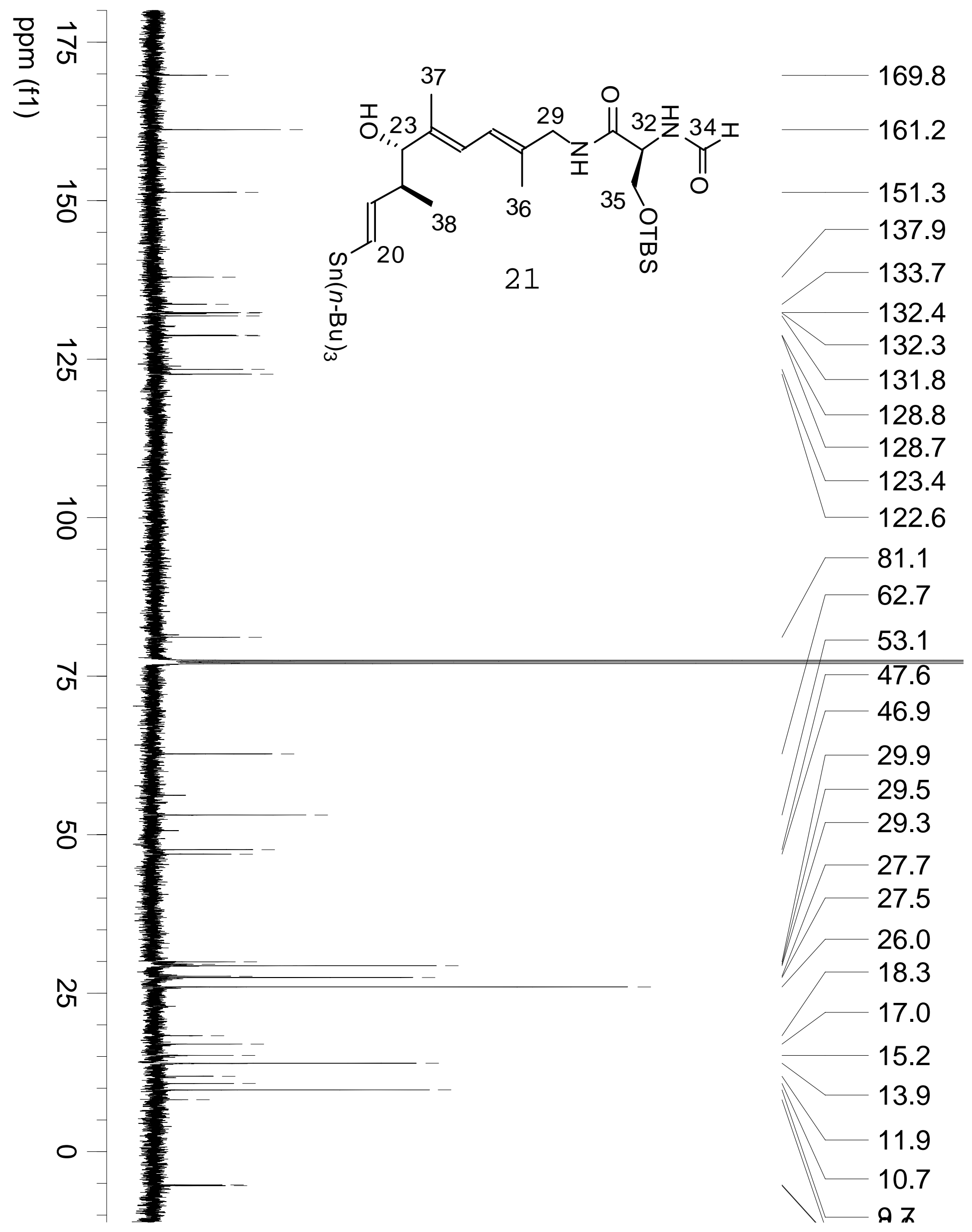




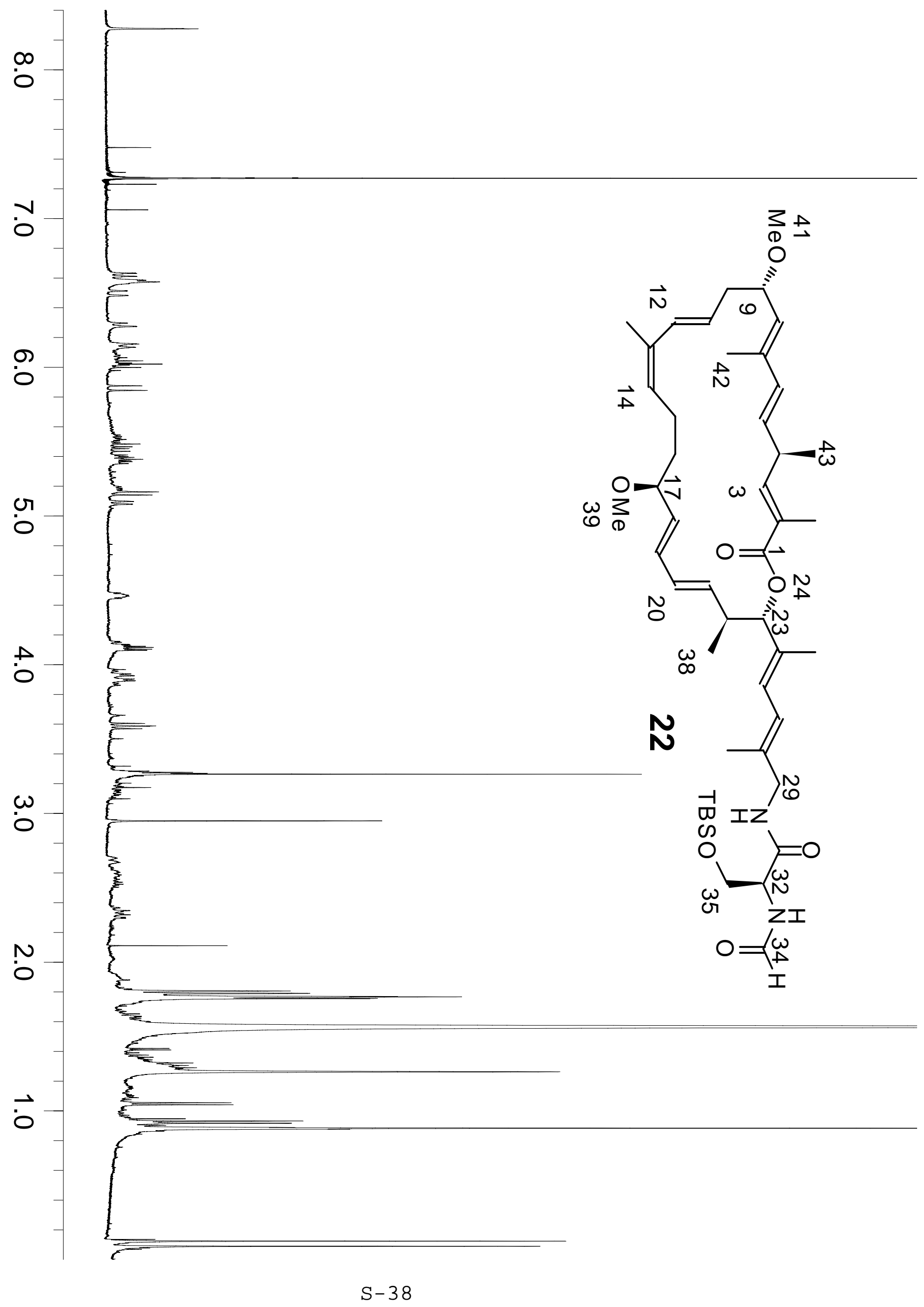




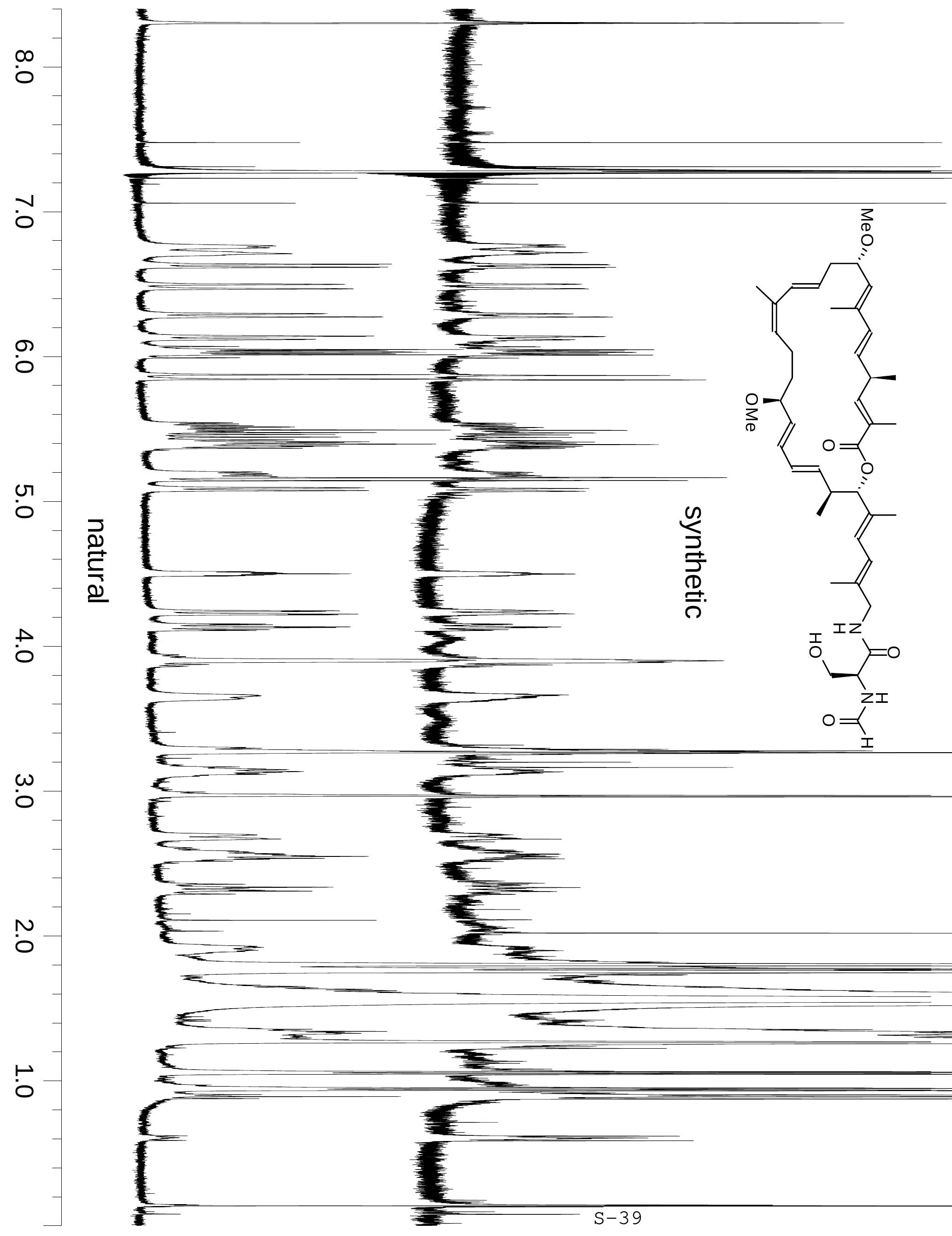

